FEDERAL RESERVE BANK OF SAN FRANCISCO

WORKING PAPER SERIES

\title{
State Investment Tax Incentives: A Zero-Sum Game?
}

\author{
Robert S. Chirinko \\ Emory University and CESifo \\ and \\ Daniel J. Wilson \\ Federal Reserve Bank of San Francisco
}

July 2008

Working Paper 2006-47

http://www.frbsf.org/publications/economics/papers/2006/wp06-47k.pdf

The views in this paper are solely the responsibility of the authors and should not be interpreted as reflecting the views of the Federal Reserve Bank of San Francisco or the Board of Governors of the Federal Reserve System. This paper was produced under the auspices for the Center for the Study of Innovation and Productivity within the Economic Research Department of the Federal Reserve Bank of San Francisco. 


\title{
State Investment Tax Incentives: A Zero-Sum Game?
}

\author{
Robert S. Chirinko \\ (University of Illinois at Chicago and CESifo) \\ and \\ Daniel J. Wilson \\ (Federal Reserve Bank of San Francisco)
}

July 2008

\begin{abstract}
* We would like to acknowledge the excellent research assistance provided by Ann Lucas and Charles Notzon and very useful comments from participants at the IFIR/CESifo Conference on New Directions in Fiscal Federalism (especially our discussant, Hanna Ågren), the 2006 North American Regional Science Council meeting (especially our discussant, Georg Grassmueck), seminars at the Federal Reserve Bank of San Francisco, University of Illinois at Urbana-Champaign, and the University of Illinois at Chicago and from Richard Arnott, three anonymous referees, and the editors. Financial support from the Federal Reserve Bank of San Francisco is gratefully acknowledged. Chirinko thanks the European University Institute for providing an excellent environment in which to complete this research. All errors and omissions remain the sole responsibility of the authors and the conclusions do not necessarily reflect the views of the organizations with which they are associated.
\end{abstract}




\title{
State Investment Tax Incentives: A Zero-Sum Game?
}

\begin{abstract}
Over the past four decades, state investment tax incentives have proliferated. This emergence of state investment tax credits (ITC) and other investment tax incentives raises two important questions: 1) Are these tax incentives effective in achieving their stated objective, to increase investment within the state?; 2) To the extent these incentives raise investment within the state, how much of this increase is due to investment drawn away from other states?

To begin to answer these questions, we construct a detailed panel dataset for 48 states for $20+$ years. The dataset contains series on output and capital, their relative prices, and establishment counts. The effects of tax variables on capital formation and establishments are measured by the Jorgensonian user cost of capital that depends in a nonlinear manner on federal and state tax variables. Cross-jurisdictional differences in state investment tax credits and state corporate tax rates entering the user cost, combined with a panel that is long in the time dimension, are key to identifying the effectiveness of state investment incentives.

Two models are estimated. The Capital Demand Model is motivated by the firstorder condition for a profit-maximizing firm and relates at the state level the capital/output ratio to the relative user cost of capital. The Twin-Counties Model exploits both the spatial breaks ("discontinuities") in tax policy at state borders and our panel dataset to relate at the county level the relative user cost to the location of manufacturing establishments. Using the Capital Demand Model, we find that own-state capital formation is substantially increased by tax-induced reductions in the own-state price of capital and, more interestingly, substantially decreased by tax-induced reductions in the price of capital in competitive-states. Similarly, using our Twin-Counties Model, we find that county manufacturing establishment counts around state borders are higher on the side of the border with the lower price of capital, but the difference is economically small, suggesting that establishments are much less mobile than overall capital. Extensions of the Capital Demand Model also reveal that state capital tax policy appears to be a zero-sum game among the states in that an equiproportionate increase in own-state and competitive-states user costs tends to have no effect on own-state capital formation.
\end{abstract}

Keywords: State Tax Incentives, Interstate Tax Competition, Business Taxation, Capital Formation, Establishment Location.

JEL Nos.: H71, H77, H25, H32

Corresponding Author

Robert S. Chirinko

Department of Finance

University of Illinois at Chicago

2333 University Hall

601 South Morgan (MC 168)

Chicago, Illinois 60607-7121

PH: 3123551262

FX: 3124137948

EM: Chirinko@uic.edu
Daniel J. Wilson

Research Department

Federal Reserve Bank of

San Francisco

101 Market Street

San Francisco, CA 94105

PH: 4159743423

FX: 4159742168

EM: Daniel.Wilson@sf.frb.org 


\section{State Investment Tax Incentives: A Zero-Sum Game?}

\section{Table of Contents}

1. Introduction

2. Panel Dataset

3. Capital Demand Model

1. Estimating Equation

2. The Role of the Relative User Cost

3. Robustness Checks

1. Alternative Competitive States

2. Alternative Specifications of the Estimating Equation

3. Additional Regressors

4. Alternative Specifications of the User Cost

5. Alternative Dynamics

4. Zero-Sum Game?

4. Twin-Counties Model

1. Estimating Equation

2. The Role of the Relative User Cost

3. An Additional Test

5. Summary and Conclusions

References

Data Appendix

Figures

Tables 


\section{State Investment Tax Incentives: A Zero-Sum Game?}

\section{Introduction}

Over the past four decades, state investment tax incentives have proliferated (Chirinko and Wilson, 2007a). For instance, though the U.S. federal investment tax credit (ITC) was permanently repealed in 1986, ITCs at the state level have grown dramatically. As shown in Figure $1,40 \%$ of states now offer a general, state-wide tax credit on investment in machinery and buildings, and the average rate of this credit exceeds 6 percentage points in 2004 . The abundance of this and other state investment tax incentives raises important empirical questions - are these tax incentives effective in increasing investment and other forms of economic activity within the state? Academic research is far from a consensus on this point. Fisher and Peters 1998, pp. 1213) state that "[I]n the case of the first argument [economic development incentives probably can influence firm location and expansion decisions...], the literature is massive but still inconclusive;..." In his survey paper, Wasylenko (1997, p. 38) concludes that elasticities of various forms of economic activity to tax policy "are not very reliable and change depending on which variables are included in the estimation equation or which time period is analyzed." By contrast, an overview of papers (including Wasylenko's study) presented at a conference focusing on the effectiveness of state and local taxes reports that there was general agreement that state and local policies affect economic activity within their borders, though the effects "are generally modest" (Bradbury, Kodrzycki, and Tannenwald, 1997, p. 1). A similar conclusion is reached in the encyclopedia entry by Bogart and Anderson (2005) concerning the effects of state policies on firm location. Perhaps the title of the report by McGuire (2003) best summarizes the current state of the scholarly empirical literature -- "Do Taxes Matter? Yes, No, Maybe So."

To the extent tax incentives are effective in raising investment within a state or attracting businesses to a state, a second question arises from a national perspective -- how much of this increase is due to investment being drawn away from other states? As noted by Stark and Wilson (2006), surprisingly few empirical studies have addressed this question. Understanding the source of the increase in capital formation and establishment count is important for assessing whether the increase merely reflects a zero-sum game among states and for informing discussions about the constitutionality of certain state tax incentives in light of the U.S. Constitution's Commerce Clause. ${ }^{1}$

\footnotetext{
${ }^{1}$ Regarding the Commerce Clause, see the papers in the special section of the Georgetown Journal of Law \& Public Policy (2006) and the session on "Are State Business Tax Incentive Good Public Policy?" in the Proceedings of the $99^{\text {th }}$ Annual Conference on Taxation (National Tax Association, 2007).
} 
These two questions are addressed in this paper with a comprehensive new panel dataset that we constructed covering the 48 contiguous states for $20+$ years (depending on the series). This dataset allows us to define variables tied tightly to theory and to utilize a variety of powerful econometric techniques. Panel data have the decided advantages of allowing us to control for factors such as land and infrastructure that are fixed or change slowly over time and for aggregate effects such as the business cycle. The relative scarcity of empirical research on interstate capital mobility and tax competition may be traceable in good part to the absence of comprehensive data. Section 2 describes the panel dataset that is drawn from a several sources, including the Annual Survey of Manufacturers, national data from the Bureau of Economic Analysis, and a variety of sources of information on state tax variables. Details concerning construction and sources are provided in the Data Appendix.

We then develop and estimate a series of models to understand the responses of capital stock and establishment count data to tax incentives embedded in the user cost of capital. Section 3 contains a Capital Demand Model motivated by a standard first-order condition relating the capital stock to output and the user cost of capital. We specify the latter as the ratio of a state's own user cost of capital relative to the user cost of capital for a competitive set of states. The user cost of capital is based on the Hall-Jorgenson concept that relies on the equivalence between renting and owning a durable asset. Based on this insight, durable capital can be assigned a rental price that easily incorporates a variety of tax variables and can be analyzed with the traditional tools of price theory. The tax variables affecting this rental price qua user cost are the investment tax credit rates (state and federal), the corporate income tax rates (state and federal), and the state property tax rate. We find that a state's capital formation (conditional on its output) decreases with the user cost prevailing in the state but increases with the user cost available in competitive states, thus documenting the importance of interstate capital flows, a necessary element for meaningful tax competition. State investment incentives appear to be a zero-sum game among the states in that an equiproportionate increase in own-state and competitive-states user costs tends to have no effect on own-state capital formation.

Section 4 develops and estimates the Twin-Counties Model explaining the location of manufacturing establishments at the county level. This model exploits both the spatial breaks, or "discontinuities," that occur at state borders (and the resulting "natural experiment" afforded by pairs of counties in the same geographic area but separated by a state border) and the panel structure of our data to assess the effects of tax policy as reflected in the user cost. Comparing the differential outcomes of county pairs with similar nonpolicy conditions but differing state policies 
is akin to the twin studies employed frequently in labor economics and medical research. The Twin-Counties Model uncovers a statistically significant, though economically small, effect of user costs prevailing at the state level on the location of establishments at the county level. Moreover, this small effect vanishes as the distance between paired-counties increases. These findings suggest that manufacturing establishments are much less geographically mobile than overall capital.

Section 5 summarizes and concludes. 


\section{The Panel Dataset}

The data constructed for and used in this paper measure economic activity in the manufacturing sector for the 48 contiguous states. This data set may be thought of as a state-level and county-level analog to other widely used data sets, such as the industry-level NBER Productivity Database, Dale Jorgenson's “KLEM” database, or the country-level Penn World Tables. This section provides a cursory overview of the construction of the five key series used in this paper: two quantity variables (output, $\mathrm{Y}_{\mathrm{s}, \mathrm{t}}$, and the capital stock, $\mathrm{K}_{\mathrm{s}, \mathrm{t}}$, where the $s$ and $t$ subscripts denote state $\mathrm{s}$ and year $\mathrm{t}$, respectively), their tax-adjusted prices $\left(\mathrm{P}_{\mathrm{s}, \mathrm{t}}^{\mathrm{Y}}\right.$ and $\mathrm{P}_{\mathrm{s}, \mathrm{t}}^{\mathrm{K}}$, respectively), and a fifth series for establishment count $\left(\mathrm{E}_{\mathrm{c}, \mathrm{t}}\right.$, where the $c$ subscript denotes county c). The quantity series are available from 1982 to 2004; the price series from 1963 to 2004; and the establishment count series from 1977 to 2004 . Substantially more detail about the definition and construction of these and other series used in this study can be found in the Data Appendix.

The primary raw data source for the nominal output $\left(Y \$_{s, t}\right)$, nominal investment $\left(I \$_{s, t}\right)$, and the $\mathrm{E}_{\mathrm{c}, \mathrm{t}}$ series is the Annual Survey of Manufacturers (ASM) conducted by the U.S. Census Bureau. Since these series all come from a single, representative-survey-based source, they are of fairly high quality. The ASM data are collected from a large, representative sample of manufacturing establishments with one or more paid employees. The ASM manufacturing sector corresponds to NAICS sectors 31 to 33 .

The $\mathrm{Y}_{\mathrm{s}, \mathrm{t}}$ series equals $\mathrm{Y}_{\mathrm{s}, \mathrm{t}}$ deflated by a manufacturing output price index.

Capital stock data useful in economic analyses are not obtainable from raw sources but must be constructed from various series. The $\mathrm{K}_{\mathrm{s}, \mathrm{t}}$ series is computed according to a perpetual inventory formula based on real investment data $\left(\mathrm{I}_{\mathrm{s}, \mathrm{t}}\right)$ and depreciation rates. The $\mathrm{I}_{\mathrm{s}, \mathrm{t}}$ series equals $I \$_{\mathrm{s}, \mathrm{t}}$ deflated by a price index for investment.

The $\mathrm{P}_{\mathrm{s}, \mathrm{t}}^{\mathrm{K}}$ series is based on the concept introduced by Jorgenson (1963) and developed and expanded by, among others, Gravelle (1994), Hall and Jorgenson (1971), Jorgenson and Yun (2001), and King and Fullerton (1984). (These studies provide detailed discussions about the concepts and measurement pertaining to $\mathrm{P}_{\mathrm{s}, \mathrm{t}}^{\mathrm{K}}$ and its components.) This series is defined as the product of three objects reflecting taxes $\left(\mathrm{TAX}_{\mathrm{s}, \mathrm{t}}\right)$, the purchase price of the capital good $\left(\right.$ PRICE $\left._{t}\right)$, and the opportunity costs of holding depreciating capital $\left(\mathrm{OPPCOST}_{t}\right)$, 


$$
\begin{aligned}
& \mathrm{P}_{\mathrm{s}, \mathrm{t}}^{\mathrm{K}}=\mathrm{TAX}_{\mathrm{s}, \mathrm{t}} * \operatorname{PRICE}_{\mathrm{t}} * \mathrm{OPPCOST}_{\mathrm{t}} \\
& \mathrm{TAX}_{\mathrm{s}, \mathrm{t}}=1-\mathrm{ITC}_{\mathrm{s}, \mathrm{t}}^{\mathrm{L}, \mathrm{S}}-\mathrm{ITC}_{\mathrm{t}}^{\mathrm{L}, \mathrm{F}}-\left(\tau_{\mathrm{s}, \mathrm{t}}^{\mathrm{E}, \mathrm{S}}+\tau_{\mathrm{s}, \mathrm{t}}^{\mathrm{E}, \mathrm{F}}\right) \mathrm{TD}_{\mathrm{s}, \mathrm{t}} \\
& +\left(1-\left(\tau_{\mathrm{s}, \mathrm{t}}^{\mathrm{E}, \mathrm{S}}+\tau_{\mathrm{s}, \mathrm{t}}^{\mathrm{E}, \mathrm{F}}\right)\right) \mathrm{PT}_{\mathrm{s}, \mathrm{t}} \\
& \operatorname{PRICE}_{\mathrm{t}}=\mathrm{P}_{\mathrm{mfg}, \mathrm{t}}^{\mathrm{I}}, \\
& \operatorname{OPPCOST}_{\mathrm{t}}=\rho_{\mathrm{t}}+\delta_{\mathrm{mfg}, \mathrm{t}},
\end{aligned}
$$

where $\mathrm{ITC}_{\mathrm{s}, \mathrm{t}}^{\mathrm{L}, \mathrm{S}}$ and $\mathrm{ITC}_{\mathrm{t}}^{\mathrm{L}, \mathrm{F}}$ are the legislated investment tax credit rates at the state and federal levels, respectively, $\tau_{\mathrm{s}, \mathrm{t}}^{\mathrm{E}, \mathrm{S}}$ and $\tau_{\mathrm{s}, \mathrm{t}}^{\mathrm{E}, \mathrm{F}}$ are the effective corporate income tax rates at the state and federal levels, respectively, $\mathrm{TD}_{\mathrm{s}, \mathrm{t}}$ is the present value of tax depreciation allowances at the state and federal levels, $\mathrm{PT}_{\mathrm{s}, \mathrm{t}}$ is the present value of property tax payments at the state level, $\mathrm{P}_{\mathrm{mfg}, \mathrm{t}}^{\mathrm{I}}$ is the price deflator for investment in the manufacturing sector, $\rho_{t}$ is the financial cost of capital, and $\delta_{\mathrm{mfg}, \mathrm{t}}$ is the economic depreciation rate in the manufacturing sector. The $\mathrm{P}_{\mathrm{s}, \mathrm{t}}^{\mathrm{K}}$ series and its eight components are stated at annual rates and in continuous time. Note that, due to data constraints, some of the component series do not vary as fully as indicated in equation (1) (see the Data Appendix) and that, since the estimating equations will control for fixed state and time effects, only those components of $\mathrm{P}_{\mathrm{s}, \mathrm{t}}^{\mathrm{K}}$ that vary by state and over time -- most importantly, $\mathrm{ITC}_{\mathrm{s}, \mathrm{t}}^{\mathrm{L}, \mathrm{S}}, \tau_{\mathrm{s}, \mathrm{t}}^{\mathrm{E}} \mathrm{S}$, and $\mathrm{PT}_{\mathrm{s}, \mathrm{t}}{ }^{--}$will have an appreciable impact on the estimated coefficients.

The user cost of capital concept is a relative price and is defined as follows,

$$
\mathrm{UC}_{\mathrm{s}, \mathrm{t}}=\mathrm{P}_{\mathrm{s}, \mathrm{t}}^{\mathrm{K}} / \mathrm{P}_{\mathrm{s}, \mathrm{t}}^{\mathrm{Y}}
$$

where $\mathrm{P}_{\mathrm{s}, \mathrm{t}}^{\mathrm{Y}}=\mathrm{P}_{\mathrm{mfg}, \mathrm{t}}^{\mathrm{BT}, \mathrm{Y}}\left[1-\left(\tau_{\mathrm{s}, \mathrm{t}}^{\mathrm{E}, \mathrm{S}}+\tau_{\mathrm{s}, \mathrm{t}}^{\mathrm{E}, \mathrm{F}}\right)\right]$ is the price of output adjusted for corporate income taxes and $\mathrm{P}_{\mathrm{mfg}, \mathrm{t}}^{\mathrm{BT}, \mathrm{Y}}$ is the price of output before taxes.

Summary statistics for the variables entering the estimating equations are provided in Table 1. 
The extensive panel dataset used in this study has several decided benefits relative to most prior studies. It is comprehensive across all 48 contiguous states, and the detailed data on tax variables are combined according to the theoretically appropriate price of capital variable sketched above. While we realize that these tax series are plagued with measurement error, we also believe that they are among some of the most carefully constructed data for purposes of an empirical investigation of state tax policy. Interstate competition is measured alternately by geographic distance and border contiguity (both standard in the literature), as well as commodity trade flows among states. Our panel dataset is rather long in the time dimension. This characteristic allows us to document some interesting results concerning the importance of accounting for dynamic aspects of the response to tax stimuli. 


\section{Capital Demand Model}

The first of the two models assessing the impact of own-state and competitive-states tax incentives is motivated by the first-order condition for optimal capital accumulation. This condition is at the core of the vast majority of econometric equations of capital formation (Chirinko, 1993). Subsection 1 contains a derivation of the estimating equation containing the relative user cost of capital, defined as the own-state user cost relative to the competitive-states user cost. Subsection 2 explores the sensitivity of results to state and time fixed effects and to lags of the relative user cost. For these results, the competitive set of states is defined as those bordering the state in question, and the overall user cost for these competitive states is a weightedaverage of the individual user costs in those states. Subsection 3 provides several robustness checks. Subsection 4 replaces the relative user cost by separate user costs for the own-state and the competitive-states and evaluates whether state tax incentives have important interstate effects and are a zero-sum game.

\subsection{Estimating Equation}

We begin by assuming that production for state $s$ at time $t$ is characterized by the following Constant Elasticity of Substitution (CES) technology,

$$
\begin{aligned}
Y_{s, t} & =Y\left[K_{s, t}, L_{s, t}, X_{s, t}, A_{s, t}, B_{s, t}^{K}, B_{s, t}^{L}\right] \\
& =A_{s, t}\left\{\phi\left(B_{s, t}^{K} K_{s, t}\right)^{[(\sigma-1) / \sigma]}+v\left(B_{s, t}^{L} L_{s, t}\right)^{[(\sigma-1) / \sigma]}+(1-\phi-v)\left(X_{s, t}\right)^{[(\sigma-1) / \sigma]}\right\}^{[\sigma /(\sigma-1)]}
\end{aligned}
$$

where $\mathrm{Y}_{\mathrm{s}, \mathrm{t}}$ is real output, $\mathrm{K}_{\mathrm{s}, \mathrm{t}}$ is the real capital stock, $\mathrm{L}_{\mathrm{s}, \mathrm{t}}$ is the level of labor input, $\mathrm{X}_{\mathrm{s}, \mathrm{t}}$ is some fixed factor such as land or infrastructure, $\phi$ and $v$ are the distribution parameters for capital and labor, respectively, and $\sigma$ is the elasticity of substitution between capital, labor, and the fixed

factor. Technical progress is both neutral $\left(A_{s, t}\right)$, and biased for capital and labor $\left(B_{s, t}^{K}\right.$ and $B_{s, t}^{L}$, respectively). Equation (3) is homogeneous of degree one in $\mathrm{K}_{\mathrm{s}, \mathrm{t}}, \mathrm{L}_{\mathrm{s}, \mathrm{t}}$, and $\mathrm{X}_{\mathrm{s}, \mathrm{t}}$.

Constrained by the CES production function, a profit-maximizing firm chooses capital so that its marginal product equals the user cost of capital (defined above in equations (1) and (2)). Differentiating equation (3) with respect to capital and rearranging terms, we obtain the following factor demand equation for capital, 


$$
\begin{array}{r}
\mathrm{K}_{\mathrm{s}, \mathrm{t}} / \mathrm{Y}_{\mathrm{s}, \mathrm{t}}=\phi^{\sigma} \mathrm{UC}_{\mathrm{s}, \mathrm{t}}{ }^{-\sigma} \mathrm{U}_{\mathrm{s}, \mathrm{t}}, \\
\mathrm{U}_{\mathrm{s}, \mathrm{t}} \equiv \mathrm{A}_{\mathrm{s}, \mathrm{t}}^{[\sigma-1] \sigma} \mathrm{B}_{\mathrm{s}, \mathrm{t}}^{[\sigma-1] \sigma},
\end{array}
$$

where the error term, $U_{s, t}$, captures the effects of technical change. We assume that $U_{s, t}$ follows a two-way error component specification,

$$
\mathrm{U}_{\mathrm{s}, \mathrm{t}}=\exp \left[\mathrm{u}_{\mathrm{s}}+\mathrm{u}_{\mathrm{t}}+\mathrm{u}_{\mathrm{s}, \mathrm{t}}\right]
$$

where state and aggregate fixed effects are captured by $u_{s}$ and $u_{t}$, respectively, and the remaining time-varying, state-specific error, $\mathrm{u}_{\mathrm{s}, \mathrm{t}}$, may have a non-zero mean. That the dependent variable enters as a ratio allows us to avoid any estimation biases that can be introduced when the magnitudes of the variables differ substantially in the cross-section and time-series dimensions. By specifying the estimating equation in ratio form, we avoid these problems and obtain more reliable estimates of the parameters of interest. We augment the first-order condition in two ways. To allow for interstate capital flows, we replace the user cost by a relative user cost defined as the own-state user cost divided by the competitive-states user cost. Moreover, three lagged values of the relative user cost variable are included to capture dynamic responses to tax stimuli. Taking logs of equation (4) and augmenting the linear specification with lags of the relative user cost, we obtain the following estimating equation,

$$
\begin{aligned}
& \mathrm{ky}_{\mathrm{s}, \mathrm{t}}=\zeta+\alpha_{0} \operatorname{ruc}_{\mathrm{s}, \mathrm{t}}+\alpha_{1} \operatorname{ruc}_{\mathrm{s}, \mathrm{t}-1}+\alpha_{2} \mathrm{ruc}_{\mathrm{s}, \mathrm{t}-2}+\alpha_{3} \mathrm{ruc}_{\mathrm{s}, \mathrm{t}-3}+\mathrm{u}_{\mathrm{s}}+\mathrm{u}_{\mathrm{t}}+\mathrm{u}_{\mathrm{s}, \mathrm{t}}, \\
& \mathrm{ky}_{\mathrm{s}, \mathrm{t}}=\operatorname{Ln}\left[\mathrm{K}_{\mathrm{s}, \mathrm{t}} / \mathrm{Y}_{\mathrm{s}, \mathrm{t}}\right] \\
& \zeta \quad \sigma \operatorname{Ln}[\phi] \\
& \operatorname{ruc}_{\mathrm{s}, \mathrm{t}}=\mathrm{uc}_{\mathrm{s}, \mathrm{t}}^{\mathrm{own}}-\mathrm{uc}_{\mathrm{s}, \mathrm{t}}^{\mathrm{comp}} \\
& \mathrm{uc}_{\mathrm{s}, \mathrm{t}}^{\mathrm{own}}=\operatorname{Ln}\left[\mathrm{UC}_{\mathrm{s}, \mathrm{t}}\right] \\
& \mathrm{uc}_{\mathrm{s}, \mathrm{t}}^{\mathrm{comp}}=\operatorname{Ln}\left[\sum_{\mathrm{v}} \varsigma_{\mathrm{s}, \mathrm{v}} \mathrm{UC}_{\mathrm{v}, \mathrm{t}}\right]
\end{aligned}
$$




$$
\begin{aligned}
& \varsigma_{\mathrm{s}, \mathrm{v}}=\text { weights reflecting the "competitive closeness" of state v to s, } \\
& \sum_{\mathrm{v}} \varsigma_{\mathrm{s}, \mathrm{v}}=1, \\
& \Omega^{\mathrm{ruc}}=\alpha_{0}+\alpha_{1}+\alpha_{2}+\alpha_{3},
\end{aligned}
$$

where the relative user cost variable $\left(\mathrm{ruc}_{\mathrm{s}, \mathrm{t}}\right)$ is the difference in the logarithms of the own-state user cost $\left(\mathrm{uc}_{\mathrm{s}, \mathrm{t}}^{\mathrm{own}}\right)$ and competitive-states user cost $\left(\mathrm{uc}_{\mathrm{s}, \mathrm{t}}^{\mathrm{comp}}\right)$. The latter user cost is defined in equation (6f) as the logarithm of the weighted-sum of the user costs for the bordering states. The weights reflect the "competitive closeness" of the bordering states and are the inverse distance between the population centroids for state $\mathrm{s}$ and that of the bordering state $\mathrm{v}$, normalized to sum to unity. (Note that alternative definitions of $\mathrm{uc}_{\mathrm{s}, \mathrm{t}}^{\mathrm{comp}}$ will be considered in section 3.3.1.) The longrun impact of the user cost variables is assessed by $\Omega^{\text {ruc }}$, which is the sum of the $\alpha$ 's.

There are several noteworthy features of equations (6) for estimating the effects of relative state tax incentives. First, this estimating equation should be considered a reduced form. We rely on theory to motivate our specification containing the variables that allow us to answer the questions in which we are interested. Second, exogenous movements in user costs are the fundamental variation that identifies the parameters of interest. Cross-jurisdiction differences in investment tax credits, corporate tax rates, and property tax rates entering the user cost, combined with a panel that is long in the time dimension, are key to identifying the effectiveness of state investment incentives. Third, the specification is parsimonious and linear, and tax policy effects are captured by the coefficients on the current and lagged values of the relative user cost term. Fourth, the specification is robust to other factors that might affect production possibilities. For example, location and geographical features that affect productivity and are fixed through time are captured by the state fixed effect. Other state-specific factors that vary through time and that are represented by $\mathrm{X}_{\mathrm{s}, \mathrm{t}}$, such as land and infrastructure, can enter as additional factors of production. Owing to the strong separability inherent in the CES function, these factors will not distort parameter estimates from equations (6) because their effects are absorbed by the output term appearing in the first-order condition. Fifth, equation (6a) highlights the importance of state and time fixed effects, an issue that will be important in the empirical results to which we now turn. 


\subsection{The Role of the Relative User Cost}

OLS estimates of equation (6) are presented in Panel A of Table 2 for estimators that differ by the inclusion/exclusion of state and year fixed effects and by the number of lags of the independent variable. This subsection discusses the results from Panel A where the competitive user cost is defined for bordering states. We begin in columns 1 to 4 with models containing only the current value of the relative user cost. In column 1 with neither state nor time fixed effects, the coefficient on ruc $\mathrm{s}_{\mathrm{s}, \mathrm{t}}$, which is equivalent to $\Omega^{\mathrm{ruc}}$ in a model with only one relative user cost variable, is not estimated very precisely. With the inclusion of state fixed effects in column 2 , $\Omega^{\text {ruc }}$ becomes negative and more precisely estimated, but it remains statistically insignificant. Column 3 includes time fixed effects but excludes state fixed effects. The results are very similar to those in column 1 without any fixed effects. Column 4 combines both fixed effects. For this model, the $\mathrm{R}^{2}$ increases substantially, and the estimate of $\Omega^{\text {ruc }}$ equal to -.523 is statistically significant at conventional levels.

These combinations of fixed effect estimations are repeated in columns 5 to 8 and 9 to 12 for models with two and three additional lags, respectively. To enhance comparability across models, the sample is identical for all models appearing in Table 2. The pattern of the $\Omega^{\text {ruc }}$, s with respect to state and time fixed effects reported in the above paragraph is the same in these lag models. For the preferred models with both fixed effects, the $\Omega^{\text {ruc }}$ 's increase (in absolute value) with additional lags, rising from -.523 with zero lags to -.707 and -.757 with two and three lags, respectively. All of these coefficient sums are statistically significant. (Further lags of the independent variable had a negligible impact on $\Omega^{\text {ruc }}$, and those results are not reported in Table 2; however, see Section 3.3.5 for models with lagged dependent variables.)

In sum, these results reveal a statistically significant impact of individual state tax policies operating though the user cost on capital formation and highlight the critical importance of controlling for state and time fixed effects in panel data and, to a lesser extent, of including several lags of the independent variable. We conclude this section by assessing the economic significance of the investment tax credit. Specifically, we ask what would happen to the average state's capital stock if the state investment tax credit was lowered from its 2004 value to 0.0 , holding constant the competitive states' investment tax credit?" The "average state" can be

\footnotetext{
${ }^{2}$ These "back of the envelope" computations are a partial equilibrium exercise conditioned on the level of output. This assumption allows us to avoid the tricky issues associated with computing scale effects and "multipliers" in a world where states are competing for capital. Of course, we would ideally like to be able to simulate the effects of policy in a general equilibrium and hence entertain both substitution and scale effects. Such an analysis of a Harbergeresque model is well beyond the scope of this paper.
} 
defined in at least two ways. One approach defines the average in terms of all states weighted by their share of the 2004 capital stock. In this case, the hypothetical policy change would raise the user cost of capital by $0.96 \%$ and, based on $\Omega^{\text {ruc }}$ equal to -0.842 , the capital stock would be lowered by $0.81 \%{ }^{3}$ These figures reflect the non-response of many states that did not have an ITC in 2004. An alternative definition focuses only on the ITC-adopting states. In this case, the increase in the user cost and the decrease in the capital stock would be $2.78 \%$ and $2.34 \%$, respectively. The actual change in capital could be larger or smaller than these simulated results if competitive states have tax policy reactions, which could either temper or magnify the increase in the relative user cost variable. ${ }^{4}$ Whether the investment tax credit has had an economically significant impact on capital formation depends on the nature of the policy experiment.

\subsection{Robustness Checks}

The next five subsections examine the robustness of these results in several dimensions exploring the impacts of alternative definitions of the competitive states, alternative specifications that modify the baseline model, additional regressors frequently found in the literature, alternative specifications that examine the effects of individual tax components in the user cost and of average tax rates, and alternative dynamics allowing for different patterns of lagged responses.

\subsubsection{Alternative Competitive States}

The above results are based on a competitive user cost defined as the weighted average of user costs for bordering states, where the weights are the inverse distance between population centroids (equations (6f) to (6h)). We explore the robustness of these results in two ways. We

${ }^{3}$ These figures are based on the following computations for the percentage change in the user cost due to a change in state ITCs from their 2004 values to 0.0 ,

$$
\begin{aligned}
0.96 \% & =\sum_{j=1}^{48} \omega_{j}^{K}\left(\frac{\mathrm{UC}_{\mathrm{j}, 2004}\left[\mathrm{ITC}_{\mathrm{j}, 2004}=0\right]-\mathrm{UC}_{\mathrm{j}, 2004}\left[\mathrm{ITC}_{\mathrm{j}, 2004}\right]}{\mathrm{UC}_{\mathrm{j}, 2004}\left[\mathrm{ITC}_{\mathrm{j}, 2004}\right]}\right), \\
\omega_{\mathrm{j}}^{\mathrm{K}} & =\mathrm{K}_{\mathrm{j}} / \sum_{\mathrm{j}=1}^{48} \mathrm{~K}_{\mathrm{j}},
\end{aligned}
$$

and $-0.81 \%=0.96 \% *(-0.842)$, where the latter figure is based on an average of the $\Omega^{\text {ruc }}$, s from panels A, $\mathrm{B}$, and $\mathrm{C}$ of Table 2, column 12.

${ }^{4}$ Chirinko and Wilson (2007b) estimate tax reaction functions among states for various capital tax policies and find that the reaction is significantly negative, a result that would magnify the increase in the relative user cost variable. 
first expand the set of competitive states to the five closest states whose user costs are again weighted by the inverse distance between population centroids. While geographic distance is frequently used to measure transportation costs (Brakman, Garretsen, and van Marrewijk, 2001, pp. 80 to 83 ) and competitive pressures, it may not fully capture "competitive closeness." For example, for the state of California, the distances between its population centroid and those of Nebraska and Texas are approximately equal, yet we would expect Texas to be a more substantial competitor because of its size and perhaps also because of specific industries (e.g., high tech firms in Texas' Austin area and California's Silicon Valley). Our second robustness check allows all 47 states to be potential competitors to state s and then weights their user costs by the trade flows from the 47 competitive states to state s (where the weights are normalized to one).

The results for these two alternatives are presented in panels $\mathrm{B}$ and $\mathrm{C}$ of Table 2, respectively. The previously discussed results about the impact of fixed effects and the role of the user cost are largely confirmed in these models with alternative competitive states. For our preferred model with three lags and both state and time fixed effects (presented in column 12), $\Omega^{\text {ruc }}$ is $-.757(.198),-.961(.227)$, and -.809 (.206) for the models in panels A, B, and C, respectively. The estimates differ by less than one standard error and are thus robust to the alternative definitions of competitive states. ${ }^{5}$ Moreover, the results confirm the importance of including state and time fixed effects and the role of additional lags in raising $\Omega^{\text {ruc }}$ (in absolute value).

\subsubsection{Alternative Specifications of the Estimating Equation}

The baseline model is motivated by the first-order condition for capital that relates the capital/output ratio to a state's own user cost, rather than the relative user cost variable, ruc $\mathrm{c}_{\mathrm{s}, \mathrm{t}}$, that enters equation (6). To place the estimating equation on firmer structural footing, we consider an alternative specification that follows more closely from the conditions characterizing profitmaximizing behavior. Combining equations (4) and (5) and taking logs, we obtain the following relation for each of the 48 states,

$$
\mathrm{ky}_{\mathrm{s}, \mathrm{t}}=\zeta-\sigma \mathrm{uc}_{\mathrm{s}, \mathrm{t}}+\mathrm{e}_{\mathrm{s}}+\mathrm{e}_{\mathrm{t}}+\mathrm{e}_{\mathrm{s}, \mathrm{t}}
$$

\footnotetext{
${ }^{5}$ The one notable exception is in panel $\mathrm{C}$ of Table 2 (where the competitive states are weighted by trade flows). In contrast to all of the other results, the $\Omega^{\text {ruc }}$ 's for models with only state fixed effects (columns 2 , 6 , and 10) are larger than the comparable coefficients for models with both state and time fixed effects (columns 4, 8, and 12). The substantial increase in the $\mathrm{R}^{2}$ 's when time fixed effects are added to state fixed effects strongly indicates that the latter models with both fixed effects are to be preferred.
} 
Given the linear structure of equation (7), the comparable equation for a set of competitive states can be formed as a weighted-average of the first-order conditions for these states,

$$
\mathrm{ky}_{\mathrm{s}, \mathrm{t}}^{\mathrm{comp}}=\zeta-\sigma \mathrm{uc}_{\mathrm{s}, \mathrm{t}}^{\mathrm{comp}}+\mathrm{e}_{\mathrm{s}}+\mathrm{e}_{\mathrm{t}}+\mathrm{e}_{\mathrm{s}, \mathrm{t}} \text {. }
$$

Subtracting equation (8) from equation (7) and affixing the superscript own to the dependent and independent variables from equation (7), we obtain the following alternative estimating equation,

$$
\mathrm{ky}_{\mathrm{s}, \mathrm{t}}^{\mathrm{own}}-\mathrm{ky}_{\mathrm{s}, \mathrm{t}}^{\mathrm{comp}}=\zeta-\sigma \mathrm{ruc}_{\mathrm{s}, \mathrm{t}}+\mathrm{e}_{\mathrm{s}}+\mathrm{e}_{\mathrm{s}, \mathrm{t}} \text {, }
$$

where $\operatorname{ruc}_{\mathrm{s}, \mathrm{t}}=\mathrm{uc}_{\mathrm{s}, \mathrm{t}}^{\mathrm{own}}-\mathrm{uc}_{\mathrm{s}, \mathrm{t}}^{\mathrm{comp}}, \mathrm{e}_{\mathrm{t}}$ is eliminated by differencing and hence time fixed effects are not required, and $e_{s}$ and $e_{s, t}$ have been redefined appropriately. As with our baseline model, we include three lags of the independent variable and label the sum of the coefficients on the ruc $\mathrm{s}_{\mathrm{t}, \mathrm{t}}$ variable and its three lags as $\Omega^{\mathrm{ALT}}$.

Estimates of $\Omega^{\mathrm{ALT}}$ are presented in the last row of Table 2 and are very similar to the of

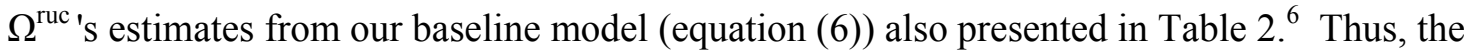
long-run impact of the relative user cost variable is robust to estimation from a model that is more closely associated with the conditions describing optimal firm behavior. ${ }^{7}$

Endogeneity is a general estimation problem that may arise because of endogenous policy choices or other factors that induce a correlation between ruc $_{\mathrm{s}, \mathrm{t}}$ and the error term. Instrumental variables are thus needed to obtain consistent parameter estimates, and we explored the possibility of generating estimates with a set of state-level political indicator variables (e.g., the political party of the governor and of the majority of both houses of the legislature) as instruments. GMM estimation of the baseline model (equation (6); not reported in the tables) yields point estimates of $\Omega^{\text {ruc }}$ that are quite similar to their OLS counterparts, though the standard errors increase sharply

\footnotetext{
${ }^{6}$ The estimates of the $\Omega^{\text {ruc }}$ 's and $\Omega^{\mathrm{ALT}}$ 's in columns $1,2,5,6,9$, and 10 cannot be compared because time fixed effects are accounted for implicitly in equation (9).

${ }^{7}$ We do not utilize equation (9) further because, while it provides an appealing econometric specification with $\operatorname{ruc}_{\mathrm{s}, \mathrm{t}}$ as the key independent variable, it does not allow us to specify a dynamic model. The problem arises because equation (9) contains two endogenous variables, $\mathrm{k}_{\mathrm{s}, \mathrm{t}}^{\mathrm{own}}$ and $\mathrm{k}_{\mathrm{s}, \mathrm{t}}^{\mathrm{comp}}$, and a tractable model that would capture the joint dynamics between these two variables is unknown to us. Given our reducedform study, we believe that dynamics may be a more important element to consider, and thus return to our baseline model, equation (6).
} 
and these sums are no longer statistically significant. In order to adequately address the endogeneity problem, the instruments must be both strongly correlated with endogenous variables and orthogonal to the error term. Though we found the political instruments to be sufficiently orthogonal to the error term (according to a standard J test; see Hansen (1982) and Sargan (1958)), the instruments turn out to be rather weak (according to the statistic proposed by Stock, Wright, and Yogo (2002) based on the first-stage F-statistic). The resulting weak instrument problem and associated adverse effects on parameter estimates thus casts doubt on these GMM results.

Another approach to control for endogeneity begins by noting that, insofar as various adjustment costs delay the response to a tax stimuli embedded in the relative user cost, the true effect of the contemporaneous user cost might be relatively small. (As reported below, the results for the partial adjustment models in Table 4 imply a half-life of adjustment of about 2.5 years.) Under this timing assumption, it would not be inappropriate to remove the contemporaneous regressor to attenuate the distorting effect of endogeneity.

OLS estimates of the baseline model without the contemporaneous relative user cost are very similar to those OLS estimates of the baseline model presented in columns 12 of Table 2 that contain a contemporaneous relative user cost. For the model based on bordering states, the $\Omega^{\text {ruc }}$ is -.789 (with a standard error of .183) when ruc $_{\mathrm{s}, \mathrm{t}}$ is omitted compared to -.757 (.198) when it is included. Similar comparisons exist for models based on the five closest states (-.949 (.208) vs. $-.961(.227))$ and trade flows $(-.769(.192)$ vs. $-.809(.206))$. While we are unable to isolate the impact of endogeneity with an instrumental variables estimator, these results suggest that endogeneity does not undermine our findings about an important role for the relative user cost.

\subsubsection{Additional Regressors}

The derivation of the estimating equation in section 3.1 established that the output term captures the effects of other factors impacting production possibilities and hence the demand for capital. However, the ability of output to fully capture a diverse range of effects might be compromised if, inter alia, the production function is not CES or if the representative firm assumption is not fully appropriate. Moreover, other studies in the state and regional tax incentive literature have included a variety of variables reflecting human capital, other characteristics of labor supply, and infrastructure.

In order to examine the robustness of our results, we consider the following four additional regressors: educational attainment of the population, percent of the population that is workingaged, population density, and infrastructure spending. (Details about data sources and definitions 
can be found in the Data Appendix.) In a panel model with fixed effects, a concern arises whether there will be sufficient state-specific time variation in these variables. In order to explore this issue, we first perform a variance decomposition by regressing each of the variables on state and time fixed effects. State-specific time variation equals the amount of variation remaining in the residuals from the variance decomposition (measured by $\left(1-\mathrm{R}^{2}\right)$ ). For the four variables listed above, the $\left(1-\mathrm{R}^{2}\right)$ 's are $0.053,0.098,0.003$, and 0.048 , respectively. This residual variation is quite low, and these four series exhibit very little state-specific time variation.

We then include all of these additional variables in our benchmark equation (6).

Consistent with the results from the variance decomposition, these additional regressors have a very modest impact on $\Omega^{\text {ruc }}$. When the competitive states are defined by the bordering states, the $\Omega^{\text {ruc 's without and with the additional regressors are - }} .757(.198)$ and $-.759(.195)$, respectively (standard errors in parentheses). The results are similar when the competitive states are defined by the Five Closest states $(-.961(.227)$ and $-.919(.227))$ and by trade flows $(-.809(.206)$ and $-.737(.197))$. Very similar results are obtained if each additional regressor is included ad seriatim. The robustness of our results to these additional variables is important given that they have been used frequently in prior studies.

\subsubsection{Alternative Specifications of the User Cost}

The results discussed in sections 3.2 to 3.3 .3 are based on a fairly complete description of the user cost of capital, which has a strong basis in theory and depends on several tax variables. The role of the state ITCs and other tax components in the user cost in 'driving" the results is examined in this subsection. We also study the impact of replacing the user cost by an average tax rate. Understanding these roles is important because other studies facing data limitations have had to neglect one or more components of the user cost or rely on the average tax rate in place of the more appropriate marginal user cost concept.

We isolate the effects of the components of the user cost as follows. Our specification of the user cost can be written in terms of the following state and federal tax variables (see Section 2 and the Data Appendix for a fuller discussion of the user cost),

$$
\mathrm{UC}_{\mathrm{s}, \mathrm{t}}=\mathrm{P}_{\mathrm{s}, \mathrm{t}}^{\mathrm{K}} / \mathrm{P}_{\mathrm{s}, \mathrm{t}}^{\mathrm{Y}}=\mathrm{G}\left[\mathrm{ITC}_{\mathrm{s}, \mathrm{t}}^{\mathrm{L}, \mathrm{S}}, \mathrm{ITC}_{\mathrm{t}}^{\mathrm{L}, \mathrm{F}}, \tau_{\mathrm{s}, \mathrm{t}}^{\mathrm{E}, \mathrm{S}}, \tau_{\mathrm{s}, \mathrm{t}}^{\mathrm{E}, \mathrm{F}}, \mathrm{PT} \mathrm{s}_{\mathrm{t}, \mathrm{t}}\right] / \mathrm{H}\left[\tau_{\mathrm{s}, \mathrm{t}}^{\mathrm{E}, \mathrm{S}}, \tau_{\mathrm{s}, \mathrm{t}}^{\mathrm{E}, \mathrm{F}}\right]
$$


where the $E, F, L$, and $S$ superscripts refer to effective, federal, legislated, and state, respectively, and $\mathrm{G}[$.$] and \mathrm{H}[$.$] are general functions. We proceed to isolate the contribution of a given$ component by setting that component to 0 . For example, we assess the impact of state ITCs by respecifying the user cost of capital as follows,

$$
\mathrm{UC}_{\mathrm{s}, \mathrm{t}}\left[\mathrm{ITC}_{\mathrm{s}, \mathrm{t}}^{\mathrm{L}, \mathrm{S}}=0\right]=\mathrm{G}\left[\mathrm{ITC}_{\mathrm{s}, \mathrm{t}}^{\mathrm{L}, \mathrm{S}}=0, \mathrm{ITC}_{\mathrm{t}}^{\mathrm{L}, \mathrm{F}}, \tau_{\mathrm{s}, \mathrm{t}}^{\mathrm{E}, \mathrm{S}}, \tau_{\mathrm{s}, \mathrm{t}}^{\mathrm{E}, \mathrm{F}}, \mathrm{PT} \mathrm{s}_{\mathrm{s}, \mathrm{t}}\right] / \mathrm{H}\left[\tau_{\mathrm{s}, \mathrm{t}}^{\mathrm{E}, \mathrm{S}}, \tau_{\mathrm{s}, \mathrm{t}}^{\mathrm{E}, \mathrm{F}}\right]
$$

We then compare estimates of $\Omega^{\text {ruc }}$ based on the "true" user cost (equation (10)) and this restricted version (equation (11)) for our preferred model with current and three lagged values of the relative user cost. This exercise is repeated sequentially for each of the five tax components individually and for the state and federal investment tax credits and the corporate income tax rates taken together.

Panel A of table 3 contains estimates of $\Omega^{\text {ruc }}$ from omitting the components of the user cost according to the procedure discussed above. We focus on the results in column 1, where the competitive states are defined by bordering states; the results are robust to alternative definitions of the competitive states presented in columns 2 and 3 . The first row reproduces the results for the true user cost presented in the prior tables. The remaining rows omit one or more components of the user cost, and three key results emerge. First, while the absence of the federal ITC has little impact, omitting the state ITC leads to a substantial increase in $\Omega^{\text {ruc }}$ (in absolute value) from -.757 to -3.084 , and hence a substantial upward bias in the estimated elasticity. Second, the absence of corporate income tax rates has no appreciable effect on $\Omega^{\text {ruc }}$. Third, omitting property taxes leads to a downward bias in the estimated user cost elasticity, as $\Omega^{\text {ruc }}$ falls from -.757 to -.262 .

The results for omitting the state ITC may seem a bit surprising on two counts. First, the use of a mismeasured user cost might be expected to drive the estimated coefficient closer to zero, but the opposite result is presented in the second row of Table 3. However, this prediction holds only for classical measurement error, a model that may not be appropriate for an omitted variable in the user cost, which is a nonlinear function of several variables. Second, the results in Table 3 might suggest that state ITCs are endogenous with respect to capital formation, leading to a positive bias on the estimated effect of the relative user cost on capital formation. That is, policymakers might respond to negative shocks to in-state capital formation by increasing the 
state ITC, thus lowering the user cost However, we also find that, in an alternative regression (not shown) in which we allow only the state ITC to vary while holding the other user cost components at their means, we still obtain a negative coefficient; specifically, the estimated $\Omega^{\text {ruc }}$ is -.257 (standard error $=.174)$. We take this as evidence that, while there may well be some positive bias due to ITC endogeneity, its effect on the user cost coefficient is smaller than the true negative causal effect of ITC-induced changes in the user cost on capital formation.

Panel B of Table 3 assesses the role of average tax rates, which have been used frequently in the literature. We define average tax rates as state government tax revenues divided by the state private gross operating surplus; the second definition of the average tax rate adds state property tax revenues to the numerator (see the Data Appendix for details). We find that, relative to our preferred specification based on the user cost, average tax rates are unrelated to capital formation. None of the coefficient sums is statistically significant at conventional levels.

Our overall conclusion is that important biases can occur when certain tax variables are omitted and that much is gained by a careful specification of the user cost of capital.

\subsubsection{Alternative Dynamics}

Lagged responses play an important role in our results. This sub-section explores the impact of some additional models of dynamics and the role of a lagged dependent variable. We begin with the ideal specification (omitting constant and error terms for notational convenience),

$$
\begin{gathered}
\mathrm{ky}_{\mathrm{s}, \mathrm{t}}=\sum_{\mathrm{h}=0}^{\mathrm{H}^{*}} \alpha_{\mathrm{h}} \mathrm{ruc}_{\mathrm{s}, \mathrm{t}-\mathrm{h}}, \\
\Omega^{\mathrm{ruc}}=\sum_{\mathrm{h}=0}^{\mathrm{H}^{*}} \alpha_{\mathrm{h}}
\end{gathered}
$$

where the ideal length of the lag $\left(\mathrm{H}^{*}\right)$ may be very large and hence the length of the required sample $\left(\mathrm{T}^{*}\right)$ may be beyond those usually available. This is the ideal relation because the relative user cost is ultimately determining $\mathrm{ky}_{\mathrm{s}, \mathrm{t}}$ and we are not concerned about data availability.

Dynamic specification issues arise because the length of the actual sample $(T)$ is not sufficiently large in the sense that $\mathrm{T}<\mathrm{T}^{*}$. There are at least four ways to estimate the coefficients and determine the long-run response of $\mathrm{ky}_{\mathrm{s}, \mathrm{t}}$ to a change in $\mathrm{ruc}_{\mathrm{s}, \mathrm{t}}$. We could impose 
a truncation assumption that the quantitatively most important responses occur in the first $\mathrm{H}$ periods $(\mathrm{H}<\mathrm{T})$ and estimate the following equation,

$$
\mathrm{ky}_{\mathrm{s}, \mathrm{t}}=\sum_{\mathrm{h}=0}^{\mathrm{H}} \alpha_{\mathrm{h}} \mathrm{ruc}_{\mathrm{s}, \mathrm{t}-\mathrm{h}}
$$

This is our preferred specification because it avoids the Nickell (1981) bias, is linear-in-theparameters, and generates an estimate of the parameter of most interest, $\Omega^{\text {ruc }}$, whose standard error is determined by a linear combination of estimated moments. This specification generates the benchmark results discussed above, and they are reproduced in columns 1, 5, and 9 of Table 4 depending on the definition of the competitive states.

A second specification relies on the following standard assumption of the partial adjustment $\underline{\text { model, }}$

$$
\begin{aligned}
\mathrm{ky}_{\mathrm{s}, \mathrm{t}}-\mathrm{ky}_{\mathrm{s}, \mathrm{t}-1} & =\lambda\left(\mathrm{ky}_{\mathrm{s}, \mathrm{t}}^{*}-\mathrm{ky}_{\mathrm{s}, \mathrm{t}-1}\right), \\
\mathrm{ky}_{\mathrm{s}, \mathrm{t}}^{*} & =-\sigma \mathrm{ruc}_{\mathrm{s}, \mathrm{t}} \quad \Omega^{\mathrm{ruc}}=-\sigma,
\end{aligned}
$$

where $\mathrm{ky}_{\mathrm{s}, \mathrm{t}}^{*}$ is the desired capital/output ratio and the speed of adjustment is dictated by $\lambda$. Equations (14a) and (14b) can be combined and rearranged to yield the following estimating equation,

$$
\mathrm{ky}_{\mathrm{s}, \mathrm{t}}=-\Omega^{\mathrm{ruc}} \lambda \mathrm{ruc}_{\mathrm{s}, \mathrm{t}}+(1-\lambda) \mathrm{ky}_{\mathrm{s}, \mathrm{t}-1}
$$

This estimating equation is attractive in that it allows for responses over an infinite horizon for finite values of $T$. This benefit is achieved with the maintained geometric adjustment assumption in equation (14a), which has the added benefit of conserving degrees of freedom. However, there are several disadvantages to this partial adjustment specification. First, the presence of the lagged dependent variable introduces the Nickell bias, though with our long panel, this may not be a major concern (see Hsiao (2003, Section 4.2)). Second, because $\Omega^{\text {ruc }}$ is a nonlinear combination of estimated parameters, its standard error must be computed with the delta method, which has been shown to be unreliable in some contexts. Lastly, equation (14) carries the implication that 
the $\alpha$ 's decline geometrically. This implication is challenged by the pattern of unconstrained distributed lag coefficients in Table 2. Reasonable arguments can be made on behalf of either model, though we favor the one based on the truncation assumption.

Fortunately, as an empirical matter, we do not need to choose between these models and their underlying assumptions. The empirical results for the standard partial adjustment model are presented in columns 2, 6, and 10 of Table 5, and they are similar to those from our preferred specification with differences well less than one standard error. The speed of adjustment (as determined by $\lambda$ ) is quite slow with a half-life of 2.5 years. The important concern with the results from the standard partial adjustment model is that the standard errors increase sharply, and the

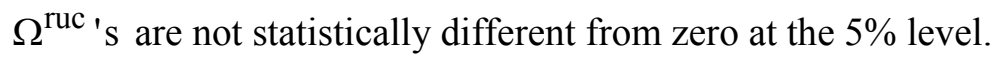

A third specification attempts to recast the partial adjustment model in a way that is more comparable to our preferred specification. The following equation can be derived from equation (14) with suitable recursive substitution,

$$
\mathrm{ky}_{\mathrm{s}, \mathrm{t}}=-\Omega^{\mathrm{ruc}} \lambda \sum_{\mathrm{h}=0}^{\mathrm{H}}(1-\lambda)^{\mathrm{h}} \mathrm{ruc}_{\mathrm{s}, \mathrm{t}-\mathrm{h}}+(1-\lambda)^{(\mathrm{H}+1)} \mathrm{ky}_{\mathrm{s}, \mathrm{t}-\mathrm{H}-1}
$$

This model, based on the recursiveness assumption for the partial adjustment model, is inferior to the model based on the standard assumption because it burns-up degrees of freedom with the $\mathrm{H}$ lags of the independent variable. ${ }^{8}$ However, the additional variation introduced by these lags will tend to lower standard errors. Nonlinear least squares estimates of (15) are presented in columns 3,7 , and 11 of Table 4 , and the point estimates of $\Omega^{\text {ruc }}$ s are similar to those presented previously. Relative to the standard partial adjustment model, the standard errors on the $\Omega^{\text {ruc 's }}$ are a bit lower.

Our fourth model is motivated by two concerns. While the estimation results from the two partial adjustment models are quite sensible, we believe that there is a tension between imposing the parametric restrictions associated with the partial adjustment model and the reduced form nature of our study. Moreover, the pattern of the $\alpha$ 's causes some concern because the contemporaneous coefficient is always statistically close to zero whenever additional lags are included (in models with both state and time fixed effects). This modest contemporaneous

\footnotetext{
${ }^{8}$ In order to preserve identical samples across all models, the number of lags of the independent variable used in equation (15) (and equation (16) below) is one less than that used in the preferred specification (equation (13)).
} 
response may well reflect a variety of frictions that impede immediate adjustment. These two concerns lead us to favor a less restricted partial adjustment model, though one that is motivated by theoretical considerations. An important implication of the derivation of equation (15) is the way in which the lagged dependent variable enters, and we adopt the following unrestricted specification consistent with that version of the partial adjustment model,

$$
\begin{gathered}
\mathrm{ky}_{\mathrm{s}, \mathrm{t}}=-\sum_{\mathrm{h}=0}^{\mathrm{H}} \psi_{\mathrm{h}} \mathrm{ruc}_{\mathrm{s}, \mathrm{t}-\mathrm{h}}+\chi \mathrm{ky}_{\mathrm{s}, \mathrm{t}-\mathrm{H}-1}, \\
\Omega^{\mathrm{ruc}}=\left(\sum_{\mathrm{h}=0}^{\mathrm{H}} \psi_{\mathrm{h}} /(1-\chi)\right) .
\end{gathered}
$$

This specification has the disadvantage of being ad hoc, but the advantage of allowing for the impact of responses beyond $\mathrm{H}$ periods with the presence of the lagged dependent variable.

Estimates of this unrestricted model are presented in columns 4, 8, and 12 in Table 4. The point estimates of the $\Omega^{\text {ruc }}$ 's are similar to those discussed previously, with the possible exception of the estimates in column 8 of -1.129 . Nonetheless, this estimate differs by less than one standard error relative to our preferred specification in column 5. As expected, the standard error on $\Omega^{\text {ruc }}$ from the model with the lagged dependent variable is much larger than the comparable statistic from the model without the lagged dependent variable. Since we believe that a substantial amount of the adjustment will be completed in $\mathrm{H}$ periods, the benefit of including the lagged dependent variable seems small compared to the costs due to the Nickell bias and the problematic standard error on $\Omega^{\text {ruc }}$. Hence, we favor the model without the lagged dependent variable as the baseline model (i.e., the results in columns 1, 5, and 9 in Table 4), though, as documented in Table 4 , the implication for the long-run impact of the relative user cost are robust to the choice of models.

\subsection{Zero-Sum Game?}

The prior results suggest that a state's investment tax policy, relative to that of its neighboring states, strongly affects capital formation within the state. This subsection examines the separate responses of own-state capital formation to own-state and competitive-states tax policies. The latter effect allows us to quantify the extent to which interstate capital flows impede 
own-state capital formation. We estimate the following more general model with own and competitive user costs entered separately,

$$
\begin{aligned}
& \mathrm{ky}_{\mathrm{s}, \mathrm{t}}=\zeta+\beta_{0} \mathrm{uc}_{\mathrm{s}, \mathrm{t}}^{\mathrm{own}}+\beta_{1} \mathrm{uc}_{\mathrm{s}, \mathrm{t}-1}^{\mathrm{own}}+\beta_{2} \mathrm{uc}_{\mathrm{s}, \mathrm{t}-2}^{\mathrm{own}}+\beta_{3} \mathrm{uc}_{\mathrm{s}, \mathrm{t}-3}^{\mathrm{own}} \\
&+\gamma_{0} \mathrm{uc}_{\mathrm{s}, \mathrm{t}}^{\mathrm{comp}}+\gamma_{1} \mathrm{uc}_{\mathrm{s}, \mathrm{t}-1}^{\mathrm{comp}}+\gamma_{2} \mathrm{uc}_{\mathrm{s}, \mathrm{t}-2}^{\mathrm{comp}}+\gamma_{3} \mathrm{uc}_{\mathrm{s}, \mathrm{t}-3}^{\mathrm{comp}} \\
&+\mathrm{u}_{\mathrm{s}}+\mathrm{u}_{\mathrm{t}}+\mathrm{u}_{\mathrm{s}, \mathrm{t}} \\
& \Omega^{\mathrm{uc}-\mathrm{own}}= \beta_{0}+\beta_{1}+\beta_{2}+\beta_{3}, \\
& \Omega^{\mathrm{uc}-\mathrm{comp}}=\gamma_{0}+\gamma_{1}+\gamma_{2}+\gamma_{3} .
\end{aligned}
$$

The $\beta$ 's, the $\gamma^{\prime}$ s, and their respective sums, $\Omega^{\text {uc-own }}$ and $\Omega^{\text {uc-comp }}$, capture the own-state and competitive-states tax effects, respectively. Insofar as there is competition for scarce capital resources and competitive tax rates affect capital formation in state $\mathrm{s}, \Omega^{\mathrm{uc}-\mathrm{comp}}$ will be positive. Alternatively, if capital is provided perfectly elastically, then the $\gamma^{\prime}$ s and $\Omega^{\text {uc-comp }}$ will equal zero. Note that equation (17a) reduces to equation (6) under the restriction $-\beta_{\mathrm{j}}=\gamma_{\mathrm{j}} \forall \mathrm{j}$.

The results are presented in Table 5 for equations (6) and (13) with three definitions of competitive states: bordering states in columns 2 and 3, the five closest states in column 4 and 5 , and all states weighted by trade flows in column 6 and 7. As a benchmark, column 1 shows the results for the standard capital demand model containing only the own-state user cost (a special case of equation (17a) where $\gamma_{\mathrm{j}}=0 \forall \mathrm{j}$ ). The sum of the coefficients on the distributed lag of $\mathrm{uc}_{\mathrm{s}, \mathrm{t}}^{\mathrm{own}}$ is negative and significant. These results may suffer from an omitted variables bias due to the possible effects of the competitive-states user cost on own-state capital formation and ownstate user cost. Column 2 contains results from equation (6) presented previously in Table 2. Estimates based on equation (17) are presented in column 3, where the sum of the $\beta$ 's are nearly equal to the comparable sum from the constrained model in column 2. The sum of the $\gamma$ 's are positive and statistically significant. Tax incentives in bordering states have an independent impact own-state capital formation.

The results in columns 5 and 7 for the other two measures of the set of competitive states are very similar $-\Omega^{\mathrm{uc}-\mathrm{own}}$ is negative, $\Omega^{\mathrm{uc}-\mathrm{comp}}$ is positive, and both sums are statistically far from zero. These results confirm that state tax incentives have empirically important interstate effects. 
We evaluate whether these interstate effects lead to a zero-sum game by the extent to which own-state and competitive-states user cost effects cancel in terms of the following sum, $\Omega^{\text {sum }}=\Omega^{\mathrm{uc}-\mathrm{own}}+\Omega^{\mathrm{uc}-\mathrm{comp}}$. For the three definitions of competitive-states listed in Table 5, these sums (with standard errors in parentheses) equal .094 (.376), .605 (.534), and 1.110 (.749), for bordering states, the five closest states, and trade flows, respectively. Though the point estimates for the latter two are large, in no case can we reject the hypothesis that state tax policies are largely a zero-sum game. 


\section{Twin-Counties Model}

A key problem confronting applied work on the impacts of government policy is separating policy effects, which are the primary object of our analysis, from the nonpolicy effects, which are undoubtedly quantitatively important but not of immediate interest. In the previous section, we relied on the first-order condition for capital demand to suggest the appropriate specification. This section addresses the key problem in an alternative way by exploiting the spatial discontinuity that occurs at state borders to identify the effects of tax policies. This strategy was pioneered by Holmes (1998) in his study of right-to-work laws and other "probusiness" policies on the location of manufacturing activity. Our Twin-Counties Model builds on Holmes' insight, exploits the panel structure of our data, and finds a statistically significant (though economically small) effect of state tax policy on the location of establishments.

\subsection{Estimating Equation}

The essential identifying assumptions of the model are that, in comparing two counties separated by a state border, nonpolicy effects are similar while policy effects are dissimilar. The Twin-Counties Model is based on the following general decomposition for the number of manufacturing establishments in a pair of neighboring counties that are in different states, ${ }^{9}$

$$
\begin{aligned}
& \mathrm{e}_{\mathrm{c}^{\prime}, \mathrm{t}}=\alpha_{\mathrm{c}^{\prime}}+\beta_{\mathrm{t}}+\text { nonpolicy }_{\mathrm{c}^{\prime}, \mathrm{t}}+\theta \text { policy }_{\mathrm{c}^{\prime}, \mathrm{t}}+\mathrm{u}_{\mathrm{c}^{\prime}, \mathrm{t}}, \\
& \mathrm{e}_{\mathrm{c}^{\prime \prime}, \mathrm{t}}=\alpha_{\mathrm{c}^{\prime \prime}}+\beta_{\mathrm{t}}+\text { nonpolicy }_{\mathrm{c}, \mathrm{t}}+\text { policy }_{\mathrm{c}, \mathrm{t}}+\mathrm{u}_{\mathrm{c},, \mathrm{t}},
\end{aligned}
$$

where c' is the initial (or observation) county, c" the "twinned-county," $e_{c, t}$ is the logarithm of the establishment count, $\alpha_{c}$ is a county fixed effect that captures time-invariant, observable, nonpolicy factors (such as distance from the population centroid to the state border or climate) as well as time-invariant, unobservable, nonpolicy factors (such as any discontinuities induced by geographic breaks), $\beta_{\mathrm{t}}$ is a time fixed effect impacting both counties equally, nonpolicy $\mathrm{c}_{\mathrm{c}, \mathrm{t}}$ represents one or more time-varying nonpolicy variables, policy $\mathrm{c}_{\mathrm{c}, \mathrm{t}}$ can represent one or more policy variables $\mathrm{u}_{\mathrm{c}, \mathrm{t}}$ is an error term, and $\theta$ is the parameter of interest. The key identifying assumption of the model is that, around a state border, counties c' and c" are "twins" and hence nonpolicy $_{\mathrm{c}^{\prime}, \mathrm{t}}=$ nonpolicy $_{\mathrm{c},, \mathrm{t}}$. We exploit this relation by taking cross-county differences of a pair of twin-counties (denoted p),

\footnotetext{
${ }^{9}$ Data for capital and output used for the dependent variable in Section 3 are unavailable at the county level.
} 


$$
\begin{aligned}
\nabla \mathrm{e}_{\mathrm{p}, \mathrm{t}}= & \alpha_{\mathrm{p}}+\theta \nabla \text { policy }_{\mathrm{p}, \mathrm{t}}+\mathrm{u}_{\mathrm{p}, \mathrm{t}} \\
& \nabla \mathrm{e}_{\mathrm{p}, \mathrm{t}} \equiv \mathrm{e}_{\mathrm{c}^{\prime}, \mathrm{t}}-\mathrm{e}_{\mathrm{c}^{\prime \prime}, \mathrm{t}} \\
& \nabla \text { policy }_{\mathrm{p}, \mathrm{t}} \equiv \text { policy }_{\mathrm{c}^{\prime}, \mathrm{t}}-\text { policy }_{\mathrm{c}, \mathrm{t}}
\end{aligned}
$$

where the county fixed effects have been absorbed into $\alpha_{\mathrm{p}}$, the $\beta_{\mathrm{t}}$ 's cancel by construction, and the time-varying nonpolicy variables cancel by the twins assumption.

Equation (19) is our general estimator, which in theory can be used to identify the effect of any space- and time-varying policy variable. We apply this estimator to the problem at handidentifying the effect of state investment tax incentives - by measuring $\nabla$ policy $_{\mathrm{p}, \mathrm{t}}$ as $\nabla$ policy $_{\mathrm{p}, \mathrm{t}} \equiv \mathrm{uc}_{\mathrm{c}^{\prime}, \mathrm{t}}-\mathrm{uc}_{\mathrm{c}^{\prime \prime}, \mathrm{t}} \equiv \mathrm{ruc}_{\mathrm{p}, \mathrm{t}}$, where ruc $\mathrm{p}, \mathrm{t}$ is the log relative user cost and the relative relation is drawn between a pair of twin-counties (or, more precisely, between the state tax policies prevailing in counties c' and c"). In addition to contemporaneous ruc $\mathrm{p}_{\mathrm{p}, \mathrm{t}}$, we also add three lags to the estimating equation, as we did with the models in Section 3, to allow for dynamic responses to tax policy. The final estimating equation then becomes,

$$
\begin{gathered}
\nabla \mathrm{e}_{\mathrm{p}, \mathrm{t}}=\alpha_{\mathrm{p}}+\sum_{\mathrm{s}=0}^{3} \theta_{\mathrm{s}} \mathrm{ruc}_{\mathrm{p}, \mathrm{t}-\mathrm{s}}+\mathrm{u}_{\mathrm{p}, \mathrm{t}} \\
\Omega^{\mathrm{ruc}}=\theta_{0}+\theta_{1}+\theta_{2}+\theta_{3} .
\end{gathered}
$$

If state tax investment incentives are effective, the sum of the $\theta$ 's, denoted by $\Omega^{\text {ruc }}$ in equation (20b), should be negative, statistically significant, and economically important. ${ }^{10}$

The estimation strategy in our Twin-Counties Model is related to other approaches. Comparing differential outcomes of pairs of counties with common geographic conditions but different state policies is akin to the twin studies employed frequently in labor economics and medical research, which analyze the differential outcomes of identical twins with common genetic but different environmental conditions (e.g., Ashenfelter and Krueger, 1994). Matching estimators have been employed previously in regional development studies by Isserman and Merrifield (1987), Isserman and Rephann (1995), and Rosenbaum (1989). The matching

\footnotetext{
${ }^{10}$ Though it is difficult to directly compare equation (20) to the regression equations in Section 3 , since the dependent variable here is fundamentally different (establishment count vs. capital stock), this equation is in some sense akin to equation (9).
} 
estimator from the abovementioned studies would, for each county observation, select one or more comparison counties based on the propensity score from matching in terms of a set of observable variables. (Note the comparison county or counties need not be geographically near the county in question, though distance could be one of the matching variables.) Thus, the estimator matches counties based on observables but it is disadvantaged relative to the TwinCounties estimator in not being able to account for time-invariant unobservables. The essential identifying assumption underlying our Twin-Counties and Holmes' estimators is that nonpolicy factors are similar at the border. Holmes allows nonpolicy factors to vary smoothly over space by estimating polynomial functions depending on observable geographic characteristics. (Holmes' model is static and identifies the effects of time-invariant policies, such as state "right-to-work" laws.) In our framework, we continue to rely on the identifying assumption that nonpolicy effects are similar at state borders whereas policy effects differ, but we develop a different and more general model to identify policy effects. Our approach exploits time variation to permit spatial discontinuities in time-invariant, nonpolicy factors. For example, while important nonpolicy factors such as quality of the local labor force and proximity to materials suppliers, are not likely to differ much over small distances, there may be sizable breaks at certain state borders if the borders consist of major geographic barriers, such as the Mississippi River, impeding the free flow of labor and materials across the border. In contrast to Holmes' estimator, the Twin-Counties Model allows for this and other time-invariant factors.

\subsection{The Role of the Relative User Cost}

To estimate equation (20), we must have an algorithm for establishing a pair of twincounties. We proceed to identify twin-counties in the following four steps. First, we form the set of all pairs of counties. For $\mathrm{C}$ total counties in the United States, there will be $\left((\mathrm{C}-1)^{*} \mathrm{C}\right) / 2$ pairs of counties, where the subtraction of 1 adjusts for the impossibility of a county being a twin to itself and the division by 2 adjusts for redundant pairs (where a redundant pair is defined as c' pairing with c" and c" pairing with c'). In the United States, there are approximately 3,150 counties and hence about 4.5 million pairs. Second, we restrict this set to those pairs that are in bordering states. Third, for a given c' and a given bordering state, there are many potential twins in that bordering state; we choose as the twin (c") for that bordering state the county that is geographically closest to c'. Geographic distance is calculated using the Great Circle formula based on U.S. Census Bureau data on latitude and longitude of county population centroids. Note that a given county, c', may have several twin-counties, though only one per bordering state, 
because a state may have several borders. This step yields approximately 12,000 pairs, which we refer to as twin-counties.

As an example of the above procedure, consider Modoc county, which is in the Northeast corner of California. California borders three states, Oregon, Nevada, and Arizona. Our algorithm finds the Oregon county whose population centroid is closest to Modoc's population centroid and identifies this as the twin for the Modoc-Oregon (county-border) pair. The process is then repeated for finding the closest county to Modoc in Nevada and identifying this as the twin for the Modoc-Nevada (county-border) pair and, lastly, for finding the closest county to Modoc in Arizona and identifying this as the twin for the Modoc-Arizona (county-border) pair. The resulting preliminary dataset thus contains three twinned-counties for which Modoc is the initial county (c'). Since Modoc itself is close to two state borders (its population centroid is 31 miles from the Oregon border, 35 miles from the Nevada border, and 558 miles from the Arizona border), this algorithm may also generate observations in which Modoc is identified as the second (twin) county (c") and one of Modoc's twins is the initial county (c'). We exclude such redundant observations.

Estimation of equation (20) proceeds with this twin-county dataset with a fourth restriction. This restriction addresses the concern that the initial counties (c') in the above data set may in fact be very far from the border. Note the twinned-counties (c") generally will be close to the border since they are selected based on their proximity to the initial county across the border, but there is nothing so far in our selection criteria that excludes an initial county from being far from the border of its twin's state. There may also be large twinned-counties that have population centroids that happen to be somewhat distant from the state border. We thus restrict both the initial and twin-counties used in estimation to be within 40 miles of the border. ${ }^{11}$ (To return to our example of Modoc county, this restriction would eliminate the Modoc-Arizona observation.)

Tighter restrictions yield relatively small samples and imprecise estimates; looser restrictions lead to larger samples but ones containing pairs that may not satisfy the key identifying assumption for nonpolicy effects. This "40 mile border restriction," coupled with the three-step algorithm, yields 1,877 twin-counties.

The results of estimating equation (20) with OLS are shown in Table 6. The standard errors are robust to heteroskedasticity and allow for clustering within initial county (c') for a given year (using the clustering technique of Rogers (1993)); it is important to allow for such clustering since a given initial county may have more than one twin-county because it may have more than

\footnotetext{
${ }^{11}$ Data on minimum distance between county centroids and state borders come from Holmes (1998). We are grateful to Thomas Holmes for making these data available on his website.
} 
one nearby state border (e.g., the Modoc-Oregon and Modoc-Nevada observations from the above discussion). The key estimate of interest is the sum of the $\theta_{\mathrm{s}}$ 's, $\Omega^{\text {ruc }}$, which represents the long-run effect of the relative user cost on the number of manufacturing establishments. We estimate $\Omega^{\text {ruc }}$ equal to -.078 with a robust standard error of .031 . Though this coefficient is statistically significant, in economic terms it is quite small. We return to the policy experiment discussed in Section 3.2 that evaluated the change in the average state's capital stock if the state investment tax credit was lowered from its 2004 value to 0.0 , holding constant the competitive states' investment tax credit. Recall that when the average state is computed for the 19 ITC-adopter states, the user cost would rise by $2.78 \%$. With an $\Omega^{\text {ruc }}$ value equal to -.078 , this $2.78 \%$ rise in the user cost implies a decline in the establishment count of only $0.22 \%$. The estimated impact is even smaller when the average state is computed for 48 states; in that case, the hypothetical decline in the establishment count is just $.08 \%$.

\subsection{An Additional Test}

The Twin-Counties Model permits an additional test of tax efficacy and tax competition.

We would expect relative tax policy to be more effective the closer are the paired counties, where closesness is measured by the distance between the population centroids for twin-counties, c' and c", forming a pair. Establishments in close counties (on different sides of a state border) may be more likely to respond to differential tax incentives by moving operations across the state line than establishments that are far apart. For these reasons, we would expect $\theta$ to decrease (in absolute value) as equation (20) is estimated for initial counties (c') further away from the border. This monotonicity hypothesis is evaluated with the following modified version of equation (20),

$$
\nabla^{\mathrm{d}} \mathrm{e}_{\mathrm{p}, \mathrm{t}}=\alpha_{\mathrm{p}}+\sum_{\mathrm{s}=0}^{3} \theta_{\mathrm{s}}^{\mathrm{d}} \mathrm{ruc}_{\mathrm{p}, \mathrm{t}-\mathrm{s}}^{\mathrm{d}}+\mathrm{u}_{\mathrm{p}, \mathrm{t}}
$$

where the superscript $\mathrm{d}$ denotes the distance between the population centroid for the initial county (c') in a twin-county pair and the state border separating it from county c".

Identifying $\theta^{d}$ for a particular, exact value of $d$ is impossible since each initial county's $d$ is unique; rather, we consider in each regression a 40-mile sample range, or window, and let $d$ denote the midpoint of this 40-mile sample window. For instance, $d=20$ for the regression we estimated in the subsection above for which all initial counties (as well as the twinned-counties) are restricted to be between 0 and 40 miles of the border of its state and the state of its twin. A d 
of 30 would correspond to a sample range of initial counties that are between 10 and 50 miles of the state border.

To assess the monotonicity hypothesis - i.e., whether the relative user cost effect decreases (in absolute value) with $\mathrm{d}$ - we relax for the initial county the 40 mile border restriction discussed in subsection 4.2 and estimate equation (21) repeatedly for varying samples with windows further and further away from $d=20$. (This approach is similar to analyses with rolling samples frequently used in time series econometric studies.) The first regression is that same as that in the subsection 4.2, where observations are restricted to those for which the initial county is between 0 and 40 miles of the border $(d=20)$. The next regression restricts pairs to those where the initial county is between 1 and 41 miles from the border; then 2 to 42,3 to $43, \ldots$, up to 60 to 100 . In other words, we repeatedly consider 40-mile sample windows in which the midpoint of distance-to-border for the initial county increases from 20 miles to 80 miles. Note that the distance of the twinnedcounty (c") from the border does not vary; in all regressions, observations are restricted to those for which the twinned-county is within 40 miles of the border.

Estimates of $\theta^{\mathrm{d}}$ for $\mathrm{d}$ ranging from 20 to 80 are shown in Figure 2 along with $90 \%$ confidence intervals. The estimates can be divided into three regions. For $\mathrm{d}$ increasing from 20 to $57, \theta^{\mathrm{d}}$ is negative, statistically different from zero in most cases, and more or less increasing toward zero, though the path is not monotonic. As we consider counties further and further away from the border, the effect of tax policy differentials slowly dissipates. At $d=57, \theta^{d}$ crosses the zero axis and proceeds to stay close to zero until $d=68$. At this point, $\theta^{d}$ becomes increasingly negative. The non-zero estimates beyond $\mathrm{d}=68$ are somewhat puzzling and may reflect a violation of the identifying assumption of equal nonpolicy effects in twin-county pairs or perhaps the effects of alternative borders. For example, assume that $d=20$ for a Missouri county at the Missouri/Illinois border and d increases in a westerly or northwesterly direction. Since state tax policies tend to be regionally clustered at a given point in time (Chirinko and Wilson, 2007b), the $\theta^{\mathrm{d}}$ 's may be driven lower by correlations among tax incentives offered by Iowa, Kansas, and Nebraska, all of whom have state investment tax credits.

Notwithstanding this puzzle, the movement of the $\theta^{\mathrm{d}}$ 's prior to $d=68$ is consistent with the monotonicity hypothesis and can be explained by relocation or information costs increasing with distance. For firms further from the border, these frictions dominate the incentives offered by tax policy differentials, making it more difficult for firms in remote counties to take advantage of tax programs in neighboring states. 


\section{Summary and Conclusions}

This paper is motivated by the dramatic increase in state investment incentives over the last 40 years. As documented in Figure 1, investment tax credits have become increasingly large and increasingly common among states. In 2004, the average rate of the investment tax credit (for adopting states) is greater than $6 \%$. This increased usage and size of state investment credits, as well as other tax incentives, leads to two questions: Are these tax incentives effective in stimulating investment within the state? How much of this increase is due to investment drawn away from other states?

Based on a newly constructed panel dataset for the 48 contiguous states with over 20 years of data, we address these questions by analyzing capital stock and establishment count data. The Capital Demand Model relates at the state level the capital/output ratio to the relative user cost of capital, defined as the own-state user cost divided by the competitive-states user cost. Controlling for fixed time and state effects and allowing for lags prove important in obtaining economically and statistically significant user cost responses. The Twin-Counties Model relates at the county level the relative user cost of capital to the location of manufacturing establishments. Key to our estimation strategy with this model are the spatial breaks (“discontinuities") in tax policy at state borders and panel data long in the time dimension.

The estimates from these models document the quantitative importance of tax incentives and interstate capital flows, the latter a necessary element for meaningful tax competition. Using the Capital Demand Model, we find that own-state capital formation (conditional on output) is substantially increased by tax-induced reductions in the own-state price of capital and, more interestingly, substantially decreased by tax-induced reductions in the price of capital in competitive-states. Similarly, using our Twin-Counties Model, we find that county manufacturing establishment counts around state borders are higher on the side of the border with the lower price of capital. However, unlike our findings regarding state-wide capital formation, the effect of interstate differences in the price of capital on establishment counts is economically quite small, suggesting that establishments are much less mobile than overall capital. Extensions of the Capital Demand Model also reveal that state capital tax policy appears to be a zero-sum game among the states in that an equiproportionate increase in own-state and competitive-states user costs tends to have no effect on own-state capital formation.

Future research needs to focus on the channels driving interstate capital flows. The results presented in this study provide important evidence on the quantitative importance of own-state and competitive-states user costs. But further work is needed in developing structural 
econometric models that allow for a better understanding of capital flows and tax competition among states and the attending welfare consequences. 


\section{References}

Ashenfelter, Orley, and Krueger, Alan B., "Estimates of the Economic Returns to Schooling from a New Sample of Twins," American Economic Review 84 (December 1994), 1157-1173.

Bogart, William T., and Anderson, Nathan B., "Business Location and Taxation," in Joseph J. Cordes, Robert D. Ebel, and Jane G. Gravelle (eds.), The Encyclopedia of Taxation and Tax Policy, Second Edition (Washington: The Urban Institute Press, 2005), 39-41.

Bradbury, Katharine, L., Kodrzycki, Yolanda K., and Tannenwald, Robert, "The Effects of State and Local Public Policies on Economic Development: An Overview," New England Economic Review (March/April 1997), 1-12.

Brakman, Steven, Garretsen, Harry, van Marrewijk, Charles, An Introduction to Geographical Economics (Cambridge: Cambridge University Press, 2001).

Chirinko, Robert S., "Business Fixed Investment Spending: Modeling Strategies, Empirical Results, and Policy Implications," Journal of Economic Literature 31 (December 1993), 1875-1911.

Chirinko, Robert S., and Wilson, Daniel J., "State Investment Tax Incentives: What are the Facts?," National Tax Association, Proceedings of $99^{\text {th }}$ Annual Conference on Taxation (2007a), 36-44 (CD-ROM).

Chirinko, Robert S., and Wilson, Daniel J., "Tax Competition among U.S. States: Racing to the Bottom or Riding on a Seesaw?" Federal Reserve Bank of San Francisco Working Paper, 2008-03 (December 2007b).

Fisher, Peter S., and Peters, Alan H., Industrial Incentives: Competition Among American States and Cities (Kalamazoo, Michigan: W.E. Upjohn Institute for Employment Research, 1998).

The Georgetown Journal of Law \& Public Policy 4 (Winter 2006), 15-164.

Gravelle, Jane G., The Economic Effects of Taxing Capital Income (Cambridge: MIT Press, 1994).

Hall, Robert E., and Jorgenson, Dale W., "Application of the Theory of Optimum Capital Accumulation," in Gary Fromm (ed.), Tax Incentives and Capital Spending (Washington: Brookings Institution, 1971), 9-60.

Hansen, L.P., "Large Sample Properties of Generalized Method of Moments Estimators," Econometrica, 50 (1982), 1029-54.

Holmes, Thomas J., "The Effect of State Policies on the Location of Manufacturing: Evidence From State Borders," Journal of Political Economy, 106 (August 1998), 667-705.

Hsiao, Cheng, Analysis of Panel Data Second Edition (Cambridge: Cambridge University Press, 2003). 
Isserman, Andrew M., and Merrifield, John D., "Quasi-Experimental Control Group Methods for Regional Analysis: An Application to an Energy Boomtown and Growth Pole Theory," Economic Geography 63 (January 1987), 3-19.

Isserman, Andrew M., and Rephann, Terance, "The Economic Effects of the Appalachian Regional Commission," Journal of the American Planning Association 61 (Summer 1995), 345-364.

Jorgenson, Dale W., "Capital Theory and Investment Behavior," American Economic Review 53 (May 1963), 247-259; reprinted in Investment, Volume 1: Capital Theory and Investment Behavior (Cambridge: MIT Press, 1996), 1-16.

Jorgenson, Dale W., and Yun, Kun-Young, Investment Volume 3: Lifting the Burden: Tax Reform, the Cost of Capital, and U.S. Economic Growth (Cambridge: MIT Press, 2001).

King, Mervyn A., and Fullerton, Don (eds.), The Taxation of Income from Capital (Chicago: University of Chicago Press (for the NBER), 1984). 2003).

McGuire, Therese J., "Do Taxes Matter? Yes, No, Maybe So," State Tax Notes 28 (June 9,

National Tax Association, Session on "Are State Business Tax Incentive Good Public Policy?: Multi-Disciplinary Perspectives in the Wake of Cuno v. DaimlerChrysler," National Tax Association, Proceedings of $99^{\text {th }}$ Annual Conference on Taxation (2007), 22-49 (CD-ROM).

Nickell, Stephen J., "Biases in Dynamic Models with Fixed Effects," Econometrica 49 (November 1981), 1399-1416.

Rosenbaum, Paul R., "Optimal Matching for Observational Studies," Journal of the American Statistical Association 84 (December 1989), 1024-1032.

Rogers, W.H., "sg17: Regression Standard Errors in Clustered Samples," Stata Technical Bulletin 13 (1993), 19-23.

Sargan, J.D., "The Estimation of Economic Relationships using Instrumental Variables," Econometrica, 26 (1958), 393-415.

Stark, Kirk J., and Wilson, Daniel J., "What Do We Know about the Interstate Effects of State Tax Incentives?," The Georgetown Journal of Law \& Public Policy 4 (Winter 2006), 133-164.

Stock, James H., Wright, Jonathan H., and Yogo, Motohiro, "A Survey of Weak Instruments and Weak Identification in Generalized Method of Moments," Journal of Business \& Economic Statistics 20 (October 2002), 518-529.

Wasylenko, Michael, "Taxation and Economic Development: The State of the Economic Literature," New England Economic Review (March/April 1997), 37-52.

White, Halbert, "A Heteroskedasticity-Consistent Covariance Matrix Estimator and a Direct Test for Heteroskedasticity," Econometrica 48 (May 1980), 817-838. 


\section{Data Appendix ${ }^{12}$}

This appendix describes the construction of and data sources for the data used in this study. Four series describe output $\left(\mathrm{Y}_{\mathrm{s}, \mathrm{t}}\right)$ and capital $\left(\mathrm{K}_{\mathrm{s}, \mathrm{t}}\right)$, as well as their tax-adjusted prices, $\mathrm{P}_{\mathrm{s}, \mathrm{t}}^{\mathrm{Y}}$ and $\mathrm{P}_{\mathrm{s}, \mathrm{t}}^{\mathrm{K}}$, respectively. The series are for the 48 contiguous states (indexed by subscript $\mathrm{s}$ ) for the period 1963 to 2004 (indexed by subscript t), unless otherwise noted. ${ }^{13}$ Each of the above four series is described in a separate section. Section 5 describes the data sources for a series on the number of manufacturing establishments $\left(\mathrm{E}_{\mathrm{s}, \mathrm{t}}\right)$, and Section 6 describes the weights used to aggregate the user costs for competitive states, location and distance data, and several additional regressors. The general organizing principle for each section is to first define each of the series mentioned above and then discuss its components. For each component, general issues concerning the construction of the series (if pertinent) and then data sources are discussed. Section 7 contains a Legend containing abbreviations and sources.

The state data described in this paper measure economic activity in the manufacturing sector. The primary raw source data for the state-level totals of output, investment, labor and establishments counts is the Annual Survey of Manufacturers (ASM) conducted by the U.S. Census Bureau. State-level totals (which the Census Bureau refers to as "AS-3" data) are reported in the yearly volumes of the ASM publication. From 1994 onward, these data also can be found in the yearly ASM Geographic Area Statistics (ASM-GAS) publications. Hereafter, we will refer to the ASM data on state-level totals for all years as the ASM-GAS data. The ASM data are collected from a large, representative sample of manufacturing establishments with one or more paid employees. The ASM manufacturing sector corresponds to NAICS sectors 31 to 33 .

\section{OUTPUT - $\mathbf{Y}_{\mathbf{s}, \mathrm{t}}$}

Output is measured by real value added, and it is defined as nominal value added divided by a price deflator,

$$
\mathrm{Y}_{\mathrm{s}, \mathrm{t}}=\mathrm{Y} \$_{\mathrm{s}, \mathrm{t}} / \mathrm{P}_{\mathrm{mfg}, \mathrm{t}}^{\mathrm{BT}, \mathrm{Y}}
$$

\footnotetext{
${ }^{12}$ In describing the raw data, we have taken some of the text in this Data Appendix directly from government publications.

${ }^{13}$ The most notable exception is that the Annual Survey of Manufacturers was not conducted from 1979 to 1981.
} 
where $\mathrm{Y}_{\mathrm{s}, \mathrm{t}}$ is nominal value added output and $\mathrm{P}_{\mathrm{mfg}, \mathrm{t}}^{\mathrm{BT}, \mathrm{Y}}$ is the price index for manufacturing output net of sales and excise taxes but before corporate income tax adjustments. Since the $\mathrm{P}_{\mathrm{mfg}, \mathrm{t}}^{\mathrm{BT}, \mathrm{Y}}$ series is based on producer price indices, it measures average prices received by domestic producers (PPI). The $\mathrm{Y}_{\mathrm{s}, \mathrm{t}}$ series is obtained from ASM GAS (e.g., in 2004, the data are published in Table 1, column F). The $\mathrm{P}_{\mathrm{mfg}, \mathrm{t}}^{\mathrm{BT}, \mathrm{Y}}$ series is obtained from INDUSTRY, the table labeled "Chain-Type Price Indexes for Value Added by Industry," Line 12.

\section{PRICE OF OUTPUT (TAX-ADJUSTED) $-\mathbf{P}_{\mathbf{s}, \mathrm{t}}^{\mathrm{Y}}$}

The price of output (tax-adjusted) is defined as the price index for manufacturing output adjusted by the effective corporate income tax rates at the state and federal levels,

$$
\mathrm{P}_{\mathrm{s}, \mathrm{t}}^{\mathrm{Y}}=\mathrm{P}_{\mathrm{mfg}, \mathrm{t}}^{\mathrm{BT}, \mathrm{Y}}\left(1-\tau_{\mathrm{s}, \mathrm{t}}^{\mathrm{E}, \mathrm{S}}-\tau_{\mathrm{s}, \mathrm{t}}^{\mathrm{E}, \mathrm{F}}\right)
$$

where $\mathrm{P}_{\mathrm{mfg}, \mathrm{t}}^{\mathrm{BT}, \mathrm{Y}}$ is the price index for manufacturing output before tax adjustments (defined in Section 1), $\tau_{\mathrm{s}, \mathrm{t}}^{\mathrm{E}, \mathrm{S}}$ is the effective corporate income tax rate at the state level, and $\tau_{\mathrm{s}, \mathrm{t}}^{\mathrm{E}, \mathrm{F}}$ is the effective corporate income tax rate at the federal level. (As discussed below, the effective federal tax rate depends, in principle, on state tax variables, and hence is subscripted by s.) Since $\mathrm{P}_{\mathrm{mfg}, \mathrm{t}}^{\mathrm{BT}}$ is the price of output paid by purchasers (per Section 1), $\mathrm{P}_{\mathrm{s}, \mathrm{t}}^{\mathrm{Y}}$ is the price of output received by producers. The two tax components are discussed in the following subsections.

\subsection{The Effective Corporate Income Tax Rate At The State Level $-\tau_{\mathbf{s , t}}^{\mathrm{E}, \mathrm{S}}$}

The effective corporate income tax rate at the state level is lower than the legislated (or statutory) corporate income tax rate $\left(\tau_{\mathrm{t}}^{\mathrm{L}, \mathrm{S}}\right)$ due to the deductibility (in some states) against state taxable income of taxes paid to the federal government. ${ }^{14}$ Some states allow full deductibility of federal corporate income taxes from state taxable income; Iowa and Missouri allow only 50\% deductibility; and some states allow no deductibility at all. The deductibility provision in state tax

\footnotetext{
${ }^{14}$ In "corporate income" taxes we also include Texas' "franchise" tax which has a very similar tax base as the traditional corporate income tax base.
} 
codes is represented by $v_{\mathrm{s}, \mathrm{t}}=\{1.0,0.5,0.0\}$, and the provisional effective corporate income tax rate at the state level $\left(\tau_{\mathrm{s}, \mathrm{t}}^{\mathrm{\#}, \mathrm{E}, \mathrm{S}}\right)$ is as follows,

$$
\tau_{\mathrm{s}, \mathrm{t}}^{\#, \mathrm{E}, \mathrm{S}}=\tau_{\mathrm{t}}^{\mathrm{L}, \mathrm{S}}\left(1-\mathrm{v}_{\mathrm{s}, \mathrm{t}} \tau_{\mathrm{s}, \mathrm{t}}^{\#, \mathrm{E}, \mathrm{F}}\right)
$$

The effect of federal income tax deducibility is represented by the provisional effective corporate income tax rate at the federal level $\left(\tau_{\mathrm{s}, \mathrm{t}}^{\#, \mathrm{E}, \mathrm{F}}\right.$, defined below).

The $\tau_{\mathrm{s}, \mathrm{t}}^{\mathrm{L}, \mathrm{S}}$ and $v_{\mathrm{s}, \mathrm{t}}$ series are obtained from several sources. For recent years, data are obtained primarily from various issues of BOTS and STH, as well as actual state tax forms. Data for earlier years are obtained from various issues of BOTS and SFFF. Additional information has been provided by TAXFDN. Many states have multiple legislated tax rates that increase stepwise with taxable income; we measure $\tau_{t}^{\mathrm{L}, \mathrm{S}}$ with the marginal legislated tax rate for the highest income bracket.

\subsection{The Effective Corporate Income Tax Rate At The Federal Level $-\tau_{\mathbf{s , t}}^{\mathrm{E}, \mathrm{F}}$}

The effective corporate income tax rate at the federal level is lower than the legislated corporate income tax rate $\left(\tau_{\mathrm{t}}^{\mathrm{L}, \mathrm{F}}\right)$ due to the deductibility against federal taxable income of taxes paid to the state. The provisional effective corporate income tax rate at the federal level is as follows,

$$
\tau_{\mathrm{s}, \mathrm{t}}^{\#, \mathrm{E}, \mathrm{F}}=\tau_{\mathrm{t}}^{\mathrm{L}, \mathrm{F}}\left(1-\tau_{\mathrm{s}, \mathrm{t}}^{\#, \mathrm{E}, \mathrm{S}}\right)
$$

The effect of state income tax deducibility is represented by the effective corporate income tax rate at the state level. The $\tau_{\mathrm{t}}^{\mathrm{L}, \mathrm{F}}$ series is obtained from GRAVELLE, Table 2.1. Our database presents $\tau_{\mathrm{t}}^{\mathrm{L}, \mathrm{F}}$ in percentage points.

It has not generally been recognized that, owing to deductibility of taxes paid to another level of government, the effective corporate income tax rates at the state and federal levels are functionally related to each other. As shown in the above equations, these interrelationships yield 
two equations in two unknowns, and thus can be solved for the effective corporate income tax rates at the state and federal levels, respectively, as follows,

$$
\begin{aligned}
& \tau_{\mathrm{s}, \mathrm{t}}^{\mathrm{E}, \mathrm{S}}=\tau_{\mathrm{s}, \mathrm{t}}^{\mathrm{L}, \mathrm{S}}\left[1-\mathrm{v}_{\mathrm{s}, \mathrm{t}} \tau_{\mathrm{t}}^{\mathrm{L}, \mathrm{F}}\right] /\left[1-\mathrm{v}_{\mathrm{s}, \mathrm{t}} \tau_{\mathrm{s}, \mathrm{t}}^{\mathrm{L}, \mathrm{S}} \tau_{\mathrm{t}}^{\mathrm{L}, \mathrm{F}}\right], \\
& \tau_{\mathrm{s}, \mathrm{t}}^{\mathrm{E}, \mathrm{F}}=\tau_{\mathrm{t}}^{\mathrm{L}, \mathrm{F}}\left[1-\tau_{\mathrm{s}, \mathrm{t}}^{\mathrm{L}, \mathrm{S}}\right] /\left[1-\mathrm{v}_{\mathrm{s}, \mathrm{t}} \tau_{\mathrm{s}, \mathrm{t}}^{\mathrm{L}, \mathrm{S}} \tau_{\mathrm{t}}^{\mathrm{L}, \mathrm{F}}\right] .
\end{aligned}
$$

The overall corporate income tax rate is the sum of $\tau_{\mathrm{s}, \mathrm{t}}^{\mathrm{E}, \mathrm{S}}$ and $\tau_{\mathrm{s}, \mathrm{t}}^{\mathrm{E}, \mathrm{F}}$. In the limiting case where federal corporate income taxes are not deductible against state taxable income $\left(v_{\mathrm{s}, \mathrm{t}}=0\right)$, this sum reduces to the more frequently used formula, $\tau_{\mathrm{s}, \mathrm{t}}^{\mathrm{L}, \mathrm{S}}+\left(1-\tau_{\mathrm{s}, \mathrm{t}}^{\mathrm{L}, \mathrm{S}}\right) \tau_{\mathrm{t}}^{\mathrm{L}, \mathrm{F}}$.

\section{CAPITAL - $K_{s, t}$}

Capital input is measured by the real (constant-cost) replacement value of equipment (excluding software) and structures, and this series is constructed from the following perpetual inventory formula,

$$
\mathrm{K}_{\mathrm{s}, \mathrm{t}}=\mathrm{K}_{\mathrm{s}, 1981}\left(1-\delta_{\mathrm{mfg}, \mathrm{t}}\right)^{\mathrm{t}-1981}+\mathrm{I}_{\mathrm{s}, \mathrm{t}} \quad \mathrm{t}=1982, \ldots, \mathrm{T}
$$

where $\mathrm{K}_{\mathrm{s}, 1981}$ is the initial (1981) value of the real capital stock, $\delta_{\mathrm{mfg}, \mathrm{t}}$ is the geometric rate of economic depreciation (hence $\left(1-\delta_{\mathrm{mfg}, \mathrm{t}}\right)$ is the survival rate), and $\mathrm{I}_{\mathrm{s}, \mathrm{t}}$ is real total capital expenditure. The capital stock is dated end-of-period (EOP). Each component determining the capital stock is discussed in the following subsections.

\subsection{The Initial Value Of The Capital Stock $-K_{s, 1981}$}

The $\mathrm{K}_{\mathrm{s}, \tau}$ series is measured by the book value of the capital stock adjusted for inflation,

$$
\mathrm{K}_{\mathrm{s}, 1981}=\mathrm{K}_{\mathrm{s}, 1981}^{\mathrm{BV}} *\left(\mathrm{~K}_{\mathrm{mfg}, 1981}^{\mathrm{CoC}} / \mathrm{K}_{\mathrm{mfg}, 1981}^{\mathrm{HC}}\right)
$$


where $\mathrm{K}_{\mathrm{s}, 1981}^{\mathrm{BV}}$ is the book value (historical-cost) of the capital stock for state $\mathrm{s}, \mathrm{K}_{\mathrm{mfg}, 1981}^{\mathrm{CoC}}$ is the constant-cost value of the capital stock for the manufacturing sector, and $\mathrm{K}_{\mathrm{mfg}, 1981}^{\mathrm{HC}}$ is the historical-cost value of the capital stock for the manufacturing sector. All capital stock series are end-of-period. Inflation drives a wedge between book value capital stocks (based on the original purchase cost of investment) and real capital stocks useful in economic analyses. The $\left(\mathrm{K}_{\mathrm{mfg}, 1981}^{\mathrm{CoC}} / \mathrm{K}_{\mathrm{mfg}, 1981}^{\mathrm{HC}}\right)$ ratio provides an approximate adjustment for the inflation wedge based on national manufacturing industry data.

The $\mathrm{K}_{\mathrm{s}, 1981}^{\mathrm{BV}}$ series is obtained from ASM. The $\mathrm{K}_{\mathrm{mfg}, \tau}^{\mathrm{CoC}}$ series is the product of a quantity index and a base year value that converts the index into a real stock,

$$
\mathrm{K}_{\mathrm{mfg}, 1981}^{\mathrm{CoC}}=\operatorname{INDEXK}_{\mathrm{mfg}, 1981}^{\mathrm{CoC}} * \mathrm{~K}_{\mathrm{mfg}, 2000}^{\mathrm{CuC}}
$$

where INDEXK $\mathrm{mfg}_{\mathrm{m}, 1981}^{\mathrm{CoC}}$ is the 1981 value of the chain-type quantity index for the real capital stock and $\mathrm{K}_{\mathrm{mfg}, 2000}^{\mathrm{CuC}}$ is the base year (2000) value for the current-cost value of the capital stock for the manufacturing sector. The $\operatorname{INDEXK}_{\mathrm{mfg}, 1981}^{\mathrm{CoC}}$ is obtained from FIXED, Table 4.2, line 7, and this series is divided by 100 . The $\mathrm{K}_{\mathrm{mfg}, 2000}^{\mathrm{CuC}}$ datapoint is obtained from FIXED, Table 4.1, line 7. The $\mathrm{K}_{\mathrm{mfg}, 1981}^{\mathrm{HC}}$ series is obtained from FIXED, Table 4.3, line 7.

\subsection{The Rate Of Economic Depreciation $-\boldsymbol{\delta}_{\mathbf{m f g}, \mathrm{t}}$}

The $\delta_{\mathrm{mfg}, \mathrm{t}}$ series is measured by the flow of annual depreciation divided by the capital stock existing at the beginning of the year,

$$
\delta_{\mathrm{mfg}, \mathrm{t}}=\frac{\mathrm{D}_{\mathrm{mfg}, \mathrm{t}}^{\mathrm{CuC}}}{\mathrm{K}_{\mathrm{mfg}, \mathrm{t}-1}^{\mathrm{CuC}}},
$$

where $\mathrm{D}_{\mathrm{mfg}, \mathrm{t}}^{\mathrm{CuC}}$ is the current-cost flow of depreciation in manufacturing industries and $\mathrm{K}_{\mathrm{mfg}, \mathrm{t}-1}^{\mathrm{CuC}}$ is the current-cost capital stock in manufacturing industries. The $\mathrm{D}_{\mathrm{mfg}, \mathrm{t}}^{\mathrm{CuC}}$ series is obtained from FIXED, Table 4.4, line 7. The $\mathrm{K}_{\mathrm{mfg}, \mathrm{t}-1}^{\mathrm{CuC}}$ series is obtained from FIXED, Table 4.1, line 7. See 
FRAUMENI for an excellent introduction to the theoretical and empirical literature on economic depreciation and JORGENSON-2 for an analysis showing that, even if capital depreciates according to a non-geometric pattern, long-run replacement requirements tend to a geometric pattern.

\subsection{Real Total Capital Expenditure - $I_{s, t}$}

Real total capital expenditure is defined as nominal capital expenditures deflated by a price index,

$$
\begin{aligned}
& I_{\mathrm{s}, \mathrm{t}}=\frac{\mathrm{I} \$_{\mathrm{s}, \mathrm{t}}}{\mathrm{P}_{\mathrm{mfg}, \mathrm{t}}^{\mathrm{I}}}, \\
& \mathrm{I} \$_{\mathrm{s}, \mathrm{t}}=I \$_{\mathrm{s}, \mathrm{t}}^{\mathrm{NEW}}+\mathrm{I} \$_{\mathrm{s}, \mathrm{t}}^{\mathrm{USED}},
\end{aligned}
$$

where $I \$_{\mathrm{s}, \mathrm{t}}, \mathrm{I} \$_{\mathrm{s}, \mathrm{t}}^{\mathrm{NEW}}$, and $\mathrm{I} \$_{\mathrm{s}, \mathrm{t}}^{\mathrm{USED}}$ are total, new, and used nominal capital expenditures, respectively, and $\mathrm{P}_{\mathrm{mfg}, \mathrm{t}}^{\mathrm{I}}$ is the price deflator for investment for the manufacturing sector. The $I \$_{s, t}$ and $P_{m f g, t}^{I}$ series are discussed in the following subsections.

\subsubsection{Total Nominal Capital Expenditure - $\mathbf{I}_{\mathbf{s}, \mathrm{t}}$}

The $I \$_{s, t}$ series represents nominal expenditures on equipment (excluding software) and structures. The series is obtained directly from ASM-GAS (e.g, in 2004, the data are published in Table 2, column I). ${ }^{15}$

\subsubsection{Price Deflator For Investment $-\mathbf{P}_{\mathbf{m f g}, \mathrm{t}}^{\mathrm{I}}$}

The price deflator for investment is constructed as an implicit deflator,

$$
\mathrm{P}_{\mathrm{mfg}, \mathrm{t}}^{\mathrm{I}}=\frac{\mathrm{I}_{\mathrm{mfg}, \mathrm{t}}}{\mathrm{I}_{\mathrm{mfg}, \mathrm{t}}}
$$

\footnotetext{
${ }^{15}$ We uncovered an obvious data error in the ASM regarding nominal capital expenditures in 1996 for Ohio and the sum-of-states national total. Ohio published value was over $400 \%$ of Ohio's typical levels and the resulting national total was inconsistent with the national total published in the alternative ASM publication, ASM-SIGI. We filled in the 1996 Ohio data point by simply taking national manufacturing capital expenditures from the alternative ASM publication, ASM-SIGI, and subtracting the sum of capital expenditures from all other states.
} 
where $I \$_{\mathrm{mfg}, \mathrm{t}}$ and $\mathrm{I}_{\mathrm{mfg}, \mathrm{t}}$ are nominal and real total capital expenditures, respectively, for the manufacturing sector.

The $\mathrm{I}_{\mathrm{mfg}, \mathrm{t}}$ series is the product of a quantity index and a base year value that converts the index into real investment expenditures,

$$
\mathrm{I}_{\mathrm{mfg}, \mathrm{t}}=\mathrm{INDEXI}_{\mathrm{mfg}, \mathrm{t}} * \mathrm{I}_{\mathrm{mfg}, \mathrm{t}=2000}
$$

where $\mathrm{INDEXI}_{\mathrm{mfg}, \mathrm{t}}$ is the chain-type quantity index for real investment expenditures and I $\$_{\mathrm{mfg}, \mathrm{t}=2000}$ the base year value for current investment expenditures. The $\mathrm{INDEXI}_{\mathrm{mfg}, \mathrm{t}}$ is obtained from FIXED, Table 4.8, line 7, and this series is divided by 100 .

\section{PRICE OF CAPITAL (TAX-ADJUSTED) $-\mathbf{P}_{\mathbf{s}, \mathbf{t}}^{\mathbf{K}}$}

The price of capital (tax-adjusted) is defined as the product of three objects reflecting tax credits and deductions $\left(\operatorname{TAX}_{\mathrm{s}, \mathrm{t}}\right)$, the purchase price of the capital good $\left(\mathrm{PRICE}_{\mathrm{s}, \mathrm{t}}\right)$, and the opportunity costs of holding depreciating capital $\left(\operatorname{OPPCOST}_{\mathrm{s}, \mathrm{t}}\right)$,

$$
\mathrm{P}_{\mathrm{s}, \mathrm{t}}^{\mathrm{K}}=\mathrm{TAX}_{\mathrm{s}, \mathrm{t}} * \mathrm{PRICE}_{\mathrm{s}, \mathrm{t}} * \mathrm{OPPCOST}_{\mathrm{s}, \mathrm{t}} \text {, }
$$

where

$$
\begin{aligned}
\text { TAX }_{\mathrm{s}, \mathrm{t}} & =1-\mathrm{ITC}_{\mathrm{s}, \mathrm{t}}^{\mathrm{L}, \mathrm{S}}-\mathrm{ITC}_{\mathrm{t}}^{\mathrm{L}, \mathrm{F}}-\left(\tau_{\mathrm{s}, \mathrm{t}}^{\mathrm{E}, \mathrm{S}}+\tau_{\mathrm{s}, \mathrm{t}}^{\mathrm{E}, \mathrm{F}}\right) \mathrm{TD}_{\mathrm{s}, \mathrm{t}} \\
& +\left(1-\left(\tau_{\mathrm{s}, \mathrm{t}}^{\mathrm{E}, \mathrm{S}}+\tau_{\mathrm{s}, \mathrm{t}}^{\mathrm{E}, \mathrm{F}}\right)\right) \mathrm{PT}_{\mathrm{s}, \mathrm{t}}
\end{aligned}
$$

$$
\begin{aligned}
& \operatorname{PRICE}_{\mathrm{s}, \mathrm{t}}=\mathrm{P}_{\mathrm{mfg}, \mathrm{t}}^{\mathrm{I}}, \\
& \operatorname{OPPCOST}_{\mathrm{s}, \mathrm{t}}=\rho_{\mathrm{t}}+\delta_{\mathrm{mfg}, \mathrm{t}} .
\end{aligned}
$$

and where $\mathrm{ITC}_{\mathrm{s}, \mathrm{t}}^{\mathrm{L}, \mathrm{S}}$ and $\mathrm{ITC}_{\mathrm{t}}^{\mathrm{L}, \mathrm{F}}$ are the legislated investment tax credit rates at the state and

federal levels, respectively, $\tau_{\mathrm{s}, \mathrm{t}}^{\mathrm{E}, \mathrm{S}}$ and $\tau_{\mathrm{t}}^{\mathrm{E}, \mathrm{F}}$ are the effective corporate income tax rates at the state and federal levels, respectively, $\mathrm{TD}_{\mathrm{s}, \mathrm{t}}$ is the present value of tax depreciation allowances at the federal level, $\mathrm{PT}_{\mathrm{s}, \mathrm{t}}$ is the present value of property tax payments at the state level, $\mathrm{P}_{\mathrm{mfg}, \mathrm{t}}^{\mathrm{I}}$ is the price deflator for investment in the manufacturing sector, $\rho_{t}$ is the financial cost of capital, and 
$\delta_{\mathrm{mfg}, \mathrm{t}}$ is the economic depreciation rate. The $\mathrm{P}_{\mathrm{s}, \mathrm{t}}^{\mathrm{K}}$ series and its eight components are stated at an annual rate and in continuous time. Four of the components have been discussed previously $\tau_{\mathrm{s}, \mathrm{t}}^{\mathrm{E}, \mathrm{S}}, \tau_{\mathrm{s}, \mathrm{t}}^{\mathrm{E}, \mathrm{F}}, \mathrm{P}_{\mathrm{mfg}, \mathrm{t}}^{\mathrm{I}}$, and $\delta_{\mathrm{mfg}, \mathrm{t}}$; the remaining four components are discussed in the following subsections. Note that the user cost of capital, which was introduced by JORGENSON-1 in 1963 and extended by, among others, HALL-JORGENSON, GRAVELLE, JORGENSON-YUN, and KING-FULLERTON, equals $\mathrm{P}_{\mathrm{s}, \mathrm{t}}^{\mathrm{K}}$ divided by $\mathrm{P}_{\mathrm{s}, \mathrm{t}}^{\mathrm{Y}}$ (the latter discussed in Section 2).

\subsection{The Legislated Investment Tax Credit, State - ITC $_{\mathbf{s}, \mathrm{t}}^{\mathrm{L}, S}$}

The state investment tax credit is a credit against state corporate income tax liabilities. In general, the effective amount of the investment tax credit is simply the legislated investment tax credit rate $\left(\mathrm{ITC}_{\mathrm{S}, \mathrm{t}}^{\mathrm{L}, \mathrm{S}}\right)$ multiplied by the value of capital expenditures put into place within the state in a tax year. The effective rate is lower than the legislated rate in a handful of states for two reasons. First, five states (Connecticut, Idaho, Maine, North Carolina, and Ohio) permit the state investment tax credit to be applied only to equipment. Since equipment investment is approximately $85 \%$ of ASM total national investment, we multiply $\operatorname{ITC}_{\mathrm{s}, \mathrm{t}}^{\mathrm{L}, \mathrm{S}}$ by 0.85 for these five states. Second, states generally require basis adjustments deducting the amount of the credit from the asset basis for depreciation purposes; this adjustment is considered in the subsection on the Present Value of Tax Depreciation Allowances.

The $\mathrm{ITC}_{\mathrm{s}, \mathrm{t}}^{\mathrm{L}, \mathrm{S}}$ series is obtained directly from states' online corporate tax forms and instructions. For most states with an investment tax credit, both current and historical credit rates are provided in the current year instructions (since companies applying for a credit based on some past year's investment apply that year's credit rate rather than the current rate). In those few cases where some or all historical rates were missing from the online forms and instructions, the missing rates are obtained via direct communication with the state's department of taxation. In some states, the legislated investment tax credit rate varies by the level of capital expenditures; we use the legislated credit rate for the highest tier of capital expenditures.

\subsection{The Legislated Investment Tax Credit Rate, Federal - ITC $\mathbf{t}^{\mathrm{L}, \mathrm{F}}$}

The federal investment tax credit enters the price of capital in a manner similar to that of $\mathrm{ITC}_{\mathrm{S}, \mathrm{t}}^{\mathrm{S}, \mathrm{F}}$ and is a credit against federal corporate income tax liabilities. In general, the effective amount of the investment tax credit is simply the legislated investment tax credit rate $\left(\operatorname{ITC}_{t}^{\mathrm{L}, \mathrm{F}}\right)$ 
multiplied by the value of capital expenditures put into place in a tax year. The effective credit rate is lower than the legislated credit rate because of basis adjustments specifying that the amount of the credit must be deducted from the asset basis for depreciation purposes; this adjustment is considered in the subsection on the Present Value of Tax Depreciation Allowances.

Legislated investment tax credit rates generally increase with asset lives (as determined by the tax authorities). Thus, the $\mathrm{ITC}_{\mathrm{t}}^{\mathrm{L}, \mathrm{F}}$ series is a weighted-average of the legislated investment tax credit rates by equipment asset type ( ITC $\left._{\mathrm{a}, \mathrm{t}}^{\mathrm{L}, \mathrm{F}}\right)$,

$$
\begin{aligned}
& \operatorname{ITC}_{t}^{\mathrm{L}, \mathrm{F}}=\sum_{\mathrm{a}=1}^{22} \omega_{\mathrm{a}, \mathrm{t}} \operatorname{ITC}_{\mathrm{a}, \mathrm{t}}^{\mathrm{L}, \mathrm{F}}, \\
& \omega_{\mathrm{a}, \mathrm{t}}=\frac{\mathrm{K}_{\mathrm{a}, \mathrm{t}-1}^{\mathrm{CuC}}}{\sum_{\mathrm{a}=1}^{22} \mathrm{~K}_{\mathrm{a}, \mathrm{t}-1}^{\mathrm{CuC}}},
\end{aligned}
$$

where the weights are the ratio of the current-cost capital stock for asset $a$ to the total over 22 nonresidential equipment assets. (Note that software assets, which are excluded from our measure of capital, are not included in the 22 nonresidential equipment assets used to compute the $\omega_{\mathrm{a}, \mathrm{t}}$ weights.) We thus assume that weights based on data for the nonresidential sector are appropriate for the manufacturing sector. Current-cost capital stocks are used in computing weights because the divisia-aggregated constant-cost capital stocks are not additive across components.

The ITC $_{a, t}^{\mathrm{L}, \mathrm{F}}$ series is obtained from GRAVELLE, Table B3. The $\mathrm{K}_{\mathrm{a}, \mathrm{t}-1}^{\mathrm{CuC}}$ series are obtained from FIXED, Table 2.1, lines 3 to 34 .

\subsection{The Present Value of Tax Depreciation Allowances - $T D_{s, t}$}

Tax depreciation allowances accrue over the useful life of the asset. We have assumed that the value of $\mathrm{TD}_{\mathrm{s}, \mathrm{t}}$ is 0.70 for all $\mathrm{s}$ and $\mathrm{t}$. We assume a slightly lower value than the average across asset types and years reported in GRAVELLE to adjust for the basis reduction by the amount of investment tax credits taken.

\subsection{The Present Value Of Property Tax Payments - $\mathbf{P T}_{\mathrm{s}, \mathrm{t}}$}

The formula for the present value of property tax payments $\left(\mathrm{PT}_{\mathrm{s}, \mathrm{t}}\right)$ is conceptually similar to the one for the present value of tax depreciation allowances. Both involve a stream of 
commitments that follow upon purchasing an asset. In the case of property taxes, this stream involves tax payments beginning in period $t$ and extending into the indefinite future based on the remaining value of the asset.

The $\mathrm{PT}_{\mathrm{s}, \mathrm{t}}$ series is constructed according to the following formula stated in continuous time,

$$
\mathrm{PT}_{\mathrm{s}, \mathrm{t}}=\int_{\mathrm{t}}^{\infty} \mathrm{e}^{-\left(\rho_{\mathrm{t}}+\delta_{\mathrm{mfg}, \mathrm{t}}\right)(\mathrm{v}-\mathrm{t})} \mathrm{ptr}_{\mathrm{s}, \mathrm{t}} \mathrm{dv}
$$

where $\rho_{\mathrm{t}}$ is the nominal discount rate equal to the financial cost of capital, $\delta_{\mathrm{mfg}, \mathrm{t}}$ is the rate of economic depreciation for the manufacturing sector, and $\mathrm{ptr}_{\mathrm{s}, \mathrm{t}}$ is the effective property tax rate on business property, which varies across states and over time. Conceptually, the variable $\mathrm{ptr}_{\mathrm{s}, \mathrm{t}}$ equals property taxes paid to the state and all its localities by businesses divided by the market value of business property. Thus, it is useful to express $\mathrm{ptr}_{\mathrm{s}, \mathrm{t}}$ as,

$$
\operatorname{ptr}_{\mathrm{s}, \mathrm{t}}=\left(0.404 * \mathrm{PTREV}_{\mathrm{s}, \mathrm{t}}\right) /\left[\left(\mathrm{K}_{\mathrm{s}, \mathrm{t}} / \sum_{\mathrm{i}} \mathrm{K}_{\mathrm{i}, \mathrm{t}}\right) * \mathrm{BUS}_{-} \mathrm{ASSETS}_{\mathrm{t}}\right]
$$

where PTREV $\mathrm{s}_{\mathrm{s}, \mathrm{t}}$ is property tax revenues of state and local governments within state $\mathrm{s}$, and BUS_ASSETS $\mathrm{t}_{\mathrm{t}}$ is tangible assets owned by the nonfarm corporate business sector (from Table B.102 of the Federal Reserve Board of Governors' Flow of Funds data). The adjustment factor, 0.404 , is an estimate of the business share of property tax revenues, according to KINGFULLERTON. Assets data is not available at the state-level; thus, as indicated in the above formula, national business assets are allocated to the states in proportion to the state's share of national capital stock.

The above equation can be integrated to obtain the following expression for the present value of property tax payments, which is similar to an annuity,

$$
\mathrm{PT}_{\mathrm{s}, \mathrm{t}}=\mathrm{ptr}_{\mathrm{s}, \mathrm{t}} /\left(\rho_{\mathrm{t}}+\delta_{\mathrm{mfg}, \mathrm{t}}\right)=\mathrm{ptr}_{\mathrm{s}, \mathrm{t}} / \mathrm{OPPCOST}_{\mathrm{t}}
$$


The series for $\mathrm{PTREV}_{\mathrm{s}, \mathrm{t}}$ is obtained from the State Government Tax Collections (STC) report of the U.S. Census Bureau. Data for earlier years was provided by U.S. Census Bureau staff upon our request.

\subsection{The Financial Cost Of Capital - $\rho$}

The financial cost of capital is the real discount rate applied to cash flows accruing over a long horizon and is assumed to be equal to 0.10 for all $\mathrm{t}$. The assumption of a $10 \%$ real rate is a bit higher than used in some other studies but reflects the higher risk premium, as measured by the CAPM $\beta$, for manufacturing firms. We base the latter assumption on the $\beta=1.45$ for the Fidelity Select Cyclical Industries Portfolio.

\section{ESTABLISHMENT COUNT - $\mathbf{E}_{\mathbf{s , t}}$}

The number of manufacturing establishments is obtained from County Business Patterns (CBP; e.g., for 2004, the data are published in row, NAICS="31-----“, column "est”). The coverage of the CBP is 1977 to 2004.

\section{MISCELLANEOUS SERIES}

\section{Weights on the Competitive User Costs}

The distance weights between state population centroids are from CENSUS.

The commodity trade flows among states are from TRANSPORT.

\section{Location and Distance Data Used in Section 4}

Latitude and longitude of county population centroids, used to calculated distance between counties, comes from CENSUS.

The data on minimum distance between county population centroids and state borders are from HOLMES. 


\section{Additional Regressors Used in Section 3.3.3}

The following two variables measure average tax rates.

$$
\mathrm{ATR}_{\mathrm{s}, \mathrm{t}}^{1}=\left(\mathrm{REV}_{\mathrm{s}, \mathrm{t}}^{\mathrm{CIT}}+\mathrm{REV}_{\mathrm{s}, \mathrm{t}}^{\mathrm{Sev}}+\mathrm{REV}_{\mathrm{s}, \mathrm{t}}^{\mathrm{LF}}\right) / \mathrm{GOS}_{\mathrm{s}, \mathrm{t}}
$$

where $\operatorname{GOS}_{\mathrm{s}, \mathrm{t}}$ is state private gross operating surplus and $\mathrm{REV}_{\mathrm{s}, \mathrm{t}}^{\mathrm{CIT}}, \mathrm{REV}_{\mathrm{s}, \mathrm{t}}^{\mathrm{Sev}}$, and $\mathrm{REV}_{\mathrm{s}, \mathrm{t}}^{\mathrm{LF}}$ are state government revenues from corporate income taxes, severance taxes, and business license fees, respectively.

$$
\mathrm{ATR}_{\mathrm{s}, \mathrm{t}}^{2}=\left(\mathrm{REV}_{\mathrm{s}, \mathrm{t}}^{\mathrm{CIT}}+\mathrm{REV}_{\mathrm{s}, \mathrm{t}}^{\mathrm{Sev}}+\mathrm{REV}_{\mathrm{s}, \mathrm{t}}^{\mathrm{LF}}+\mathrm{REV}_{\mathrm{s}, \mathrm{t}}^{\mathrm{PROP}}\right) / \mathrm{GOS}_{\mathrm{s}, \mathrm{t}} \cdot
$$

Gross operating surplus data come from REA, and state tax revenues data comes from STC.

\section{Additional Regressors Used in Section 3.3.4}

The following four variables are included in the Capital Demand Model:

Population density, measured by population per square miles. These data are obtained from CENSUS.

Educational attainment of the population, measured by the share of the states population with college education. These data were generously provided to us by Doug Miller. See MILLER for details.

Percent of the population that is working-aged, measured by the share of the states population between the years of 20 and 64. These data are obtained from CENSUS.

Infrastructure spending, measured by the log of state construction expenditures. These data are obtained from STC. 


\section{LEGEND}

ASM:

ASM-GAS:

ASM-SIGI:

BOTS:

CBP:

CENSUS:

FIXED:

HALLJORGENSON:

HOLMES:

INDUSTRY:
FRAUMENI:

GRAVELLE:

CENSUS, Annual Survey of Manufactures, Complete Volume (Various Years).

CENSUS, Annual Survey of Manufacturers, Geographic AreaStatistics (Various Years). Publications for the years 1994 to 2004 (except 1997 and 2002) are available online. These data are published on an establishment basis. The data are obtained from electronic or paper documents depending on the time period: 2004 (Census website); 2003 to 1972 (CD's purchased from Census); 1971 to 1963 (paper copies). URL: http://www.census.gov/mcd/asm-as3.html.

CENSUS, Annual Survey of Manufacturers, Statistics for Industry Groups and Industries (1996).

URL: http://www.census.gov/mcd/asm-as1.html.

The Council of State Governments, The Book of the States (The Council of State Governments : Lexington, Kentucky, Various Issues).

CENSUS, County Business Patterns.

URL: http://www.census.gov/epcd/cbp/download/cbpdownload.html.

Bureau of the Census, U.S. Department of Commerce.

URL: http://www.census.gov.

BEA, Standard Fixed Asset Tables.

URL: http://www.bea.gov/bea/dn/FA2004/SelectTable.asp.

Fraumeni, Barbara M., "The Measurement of Depreciation in the U.S. National Income and Product Accounts," Survey of Current Business 77 (July 1997), 7-23.

Gravelle, Jane G., The Economic Effects of Taxing Capital Income (Cambridge: MIT Press, 1994) plus updates kindly provided by Jane Gravelle.

Hall, Robert E., and Jorgenson, Dale W., "Application of the Theory of Optimum Capital Accumulation," in Gary Fromm (ed.), Tax Incentives and Capital Spending (Washington: Brookings Institution, 1971), 9-60.

Holmes, Thomas J., "The Effect of State Policies on the Location of Manufacturing: Evidence From State Borders," Journal of Political Economy, 106 (August 1998), 667-705 and from Holmes website, URL: http://www.econ.umn.edu/ holmes/research.html.

BEA, Gross-Domestic-Product-by-Industry Accounts. URL: http://www.bea.gov/bea/industry/gpotables.

JORGENSON-1: Jorgenson, Dale W., "Capital Theory and Investment Behavior," 
American Economic Review 53 (May 1963), 247-259; reprinted in Investment,Volume 1: Capital Theory and Investment Behavior (Cambridge: MIT Press, 1996), 1-16.

JORGENSON-2: Jorgenson, Dale W., "The Economic Theory of Replacement and Depreciation," in Willi Sellakaerts (ed.), Econometrics and Economic Theory: Essays in Honour of Jan Tinbergen (London: MacMillan, 1974), 189-222.

JORGENSON- Jorgenson, Dale W., and Yun, Kun-Young, Investment Volume 3:

YUN:

Lifting the Burden: Tax Reform, the Cost of Capital, and U.S.

Economic Growth (Cambridge: MIT Press, 2001).

KING-

FULLERTON:

King, Mervyn A., and Fullerton, Don (eds.), The Taxation of Income from Capital (Chicago: University of Chicago Press (for the NBER), 1984).

MILLER: $\quad$ Filipski, Mateusz; Miller, Douglas; Page, Marianne; and Stevens, Ann, "Understanding procyclical mortality." Mimeo, University of CaliforniaDavis.

NIPA: $\quad$ Bureau of Economic Analysis, National Income and Product Accounts Tables. URL: http://www.bea.gov/bea/dn/nipaweb/SelectTable.asp?Selected=N.

REA: $\quad$ Bureau of Economic Analysis, Regional Economic Accounts URL: http://www.bea.gov/regional.

SFFF: $\quad$ American Council on Intergovernmental Affairs, Significant Features of Fiscal Federalism (Washington, DC: American Council on Intergovernmental Affairs, Various Issues). URL (e.g., 1987): http://www.library.unt.edu/gpo/ACIR/SFFF/SFFF-1988-Vol-1.pdf.

STC

CENSUS, State Government Tax Collections report, various years. URL: http://www.census.gov/govs/www/statetax.html.

STH: $\quad$ Commerce Clearing House, State Tax Handbook (Chicago: Commerce Clearing House, Various Issues).

TAXFDN: $\quad$ Tax Foundation web site.

URL: http://www.taxfoundation.org.

TRANSPORT: $\quad$ The U.S. Bureau of Transportation Statistics, 1997 Survey of Commodity Flows. 
Figure 1. State Investment Tax Credits:

Number of States with a Credit (left vertical axis) and

Average Credit Rate (right vertical axis)

1969 to 2004

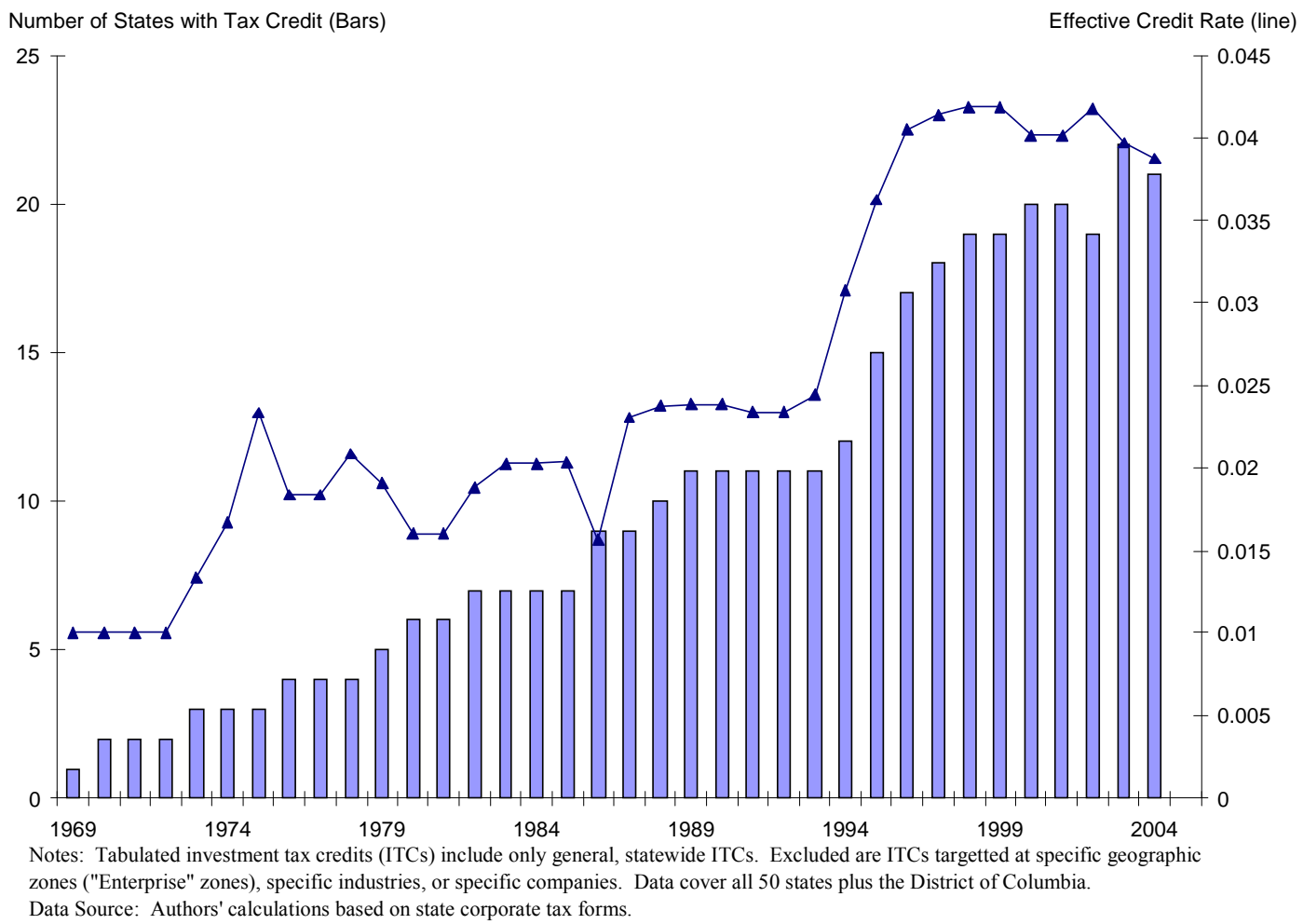


Figure 2. Coefficients on the policy variable by sample window

Dependent Variable: Cross-county percentage difference in manufacturing establishments (Dashed lines represent $90 \%$ C.I.)

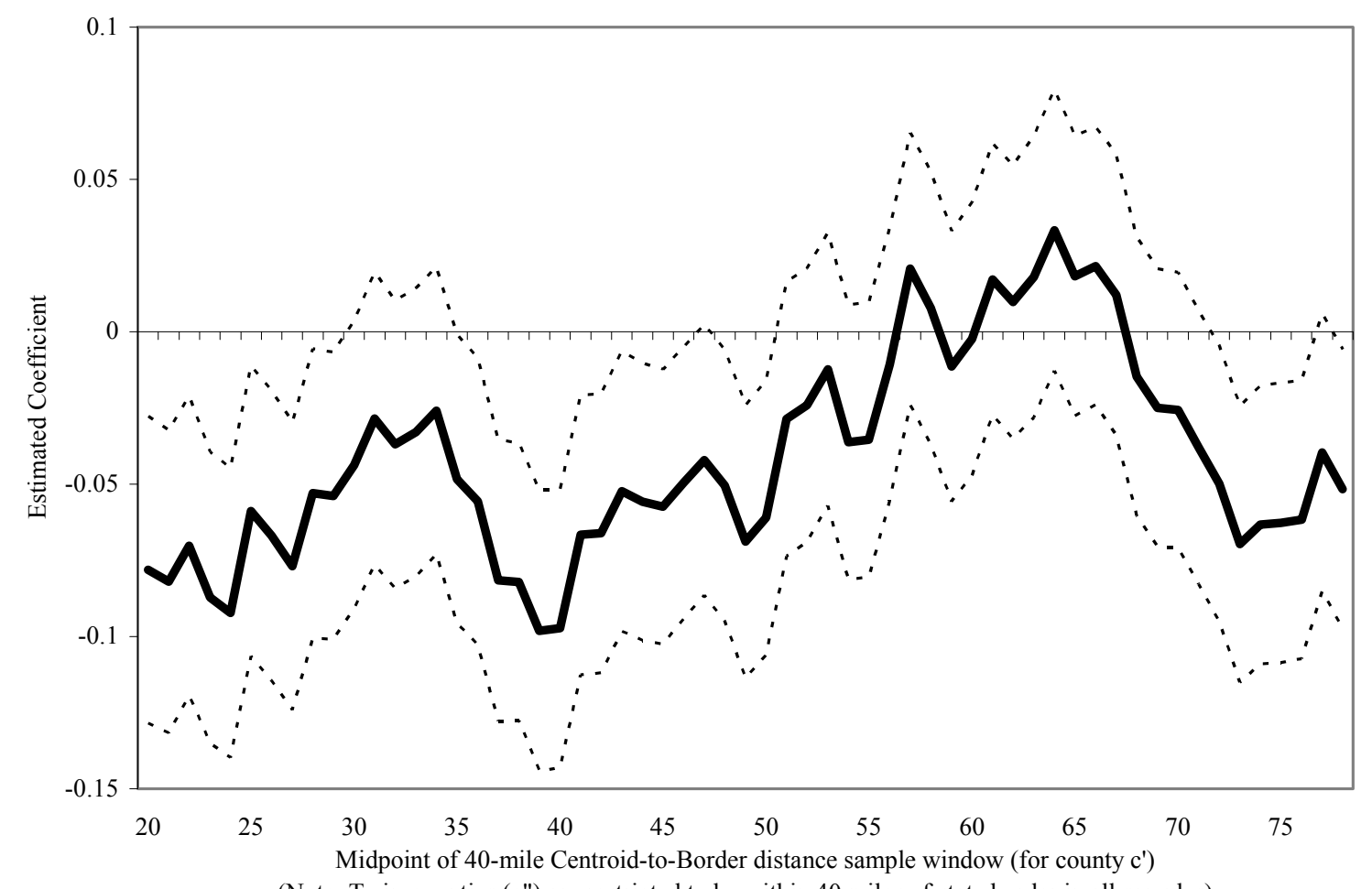

(Note: Twin-counties (c") are restricted to be within 40 miles of state border in all samples) 
Table 1: Summary Statistics

\begin{tabular}{|c|c|c|c|}
\hline & Mean & Median & $\begin{array}{l}\text { Standard } \\
\text { Deviation }\end{array}$ \\
\hline & (1) & (2) & (3) \\
\hline \multicolumn{4}{|l|}{ A. State Data } \\
\hline $\mathbf{k y}_{\mathrm{s}, \mathrm{t}}$ & -0.261 & -0.321 & 0.329 \\
\hline uc-own $n_{s, t}$ & -1.396 & -1.403 & 0.062 \\
\hline $\mathbf{U C - o w n}_{\mathrm{s}, \mathrm{t}}$ & 0.248 & 0.246 & 0.016 \\
\hline uc-comp s,t $_{\text {t }}\{$ Bordering $\}$ & -1.397 & -1.400 & 0.049 \\
\hline UC-comp $_{\mathrm{s}, \mathrm{t}}\{$ Bordering $\}$ & 0.248 & 0.247 & 0.012 \\
\hline uc-comp $_{\mathrm{s}, \mathrm{t}}\{5$ Closest $\}$ & -1.396 & -1.401 & 0.047 \\
\hline UC-comp $_{\mathrm{s}, \mathrm{t}}\{5$ Closest $\}$ & 0.248 & 0.246 & 0.012 \\
\hline uc-comp $p_{s, t}\{$ Trade $\}$ & -1.405 & -1.404 & 0.041 \\
\hline UC-comp, s $\{$ Trade $\}$ & 0.245 & 0.246 & 0.010 \\
\hline \multicolumn{4}{|l|}{ B. County Data } \\
\hline $\mathbf{e}_{\mathrm{c}, \mathrm{t}}$ & 3.537 & 3.466 & 1.476 \\
\hline $\mathbf{E}_{\mathrm{c}, \mathrm{t}}$ & 121.6 & 32.0 & 380.8 \\
\hline$\nabla \mathbf{e}_{\mathrm{p}, \mathrm{t}}\{$ Twin-Counties $\}$ & 0.015 & -0.020 & 0.510 \\
\hline
\end{tabular}

Notes to Table 1:

Summary statistics are based on panel data for 48 states for the period 1982 to 2004 for Panel A and 1977 to 2004 for Panel B. Lower-case variables are log values. Variables are defined in Section 2, in the Data Appendix, or in the tables below. The words in braces indicate whether the competitive set of states is defined by the bordering states, by the five closest states weighted by the inverse distance between a given state and its competitive states, by all states (other than a given state) weighted by trade flows, or by twin-counties. 
Table 2: Capital Demand Model. Equation (6)

Dependent Variable: Logarithm of the Capital/Output Ratio

Various Lags and Fixed Effects

A. Competitive User Cost for Bordering States

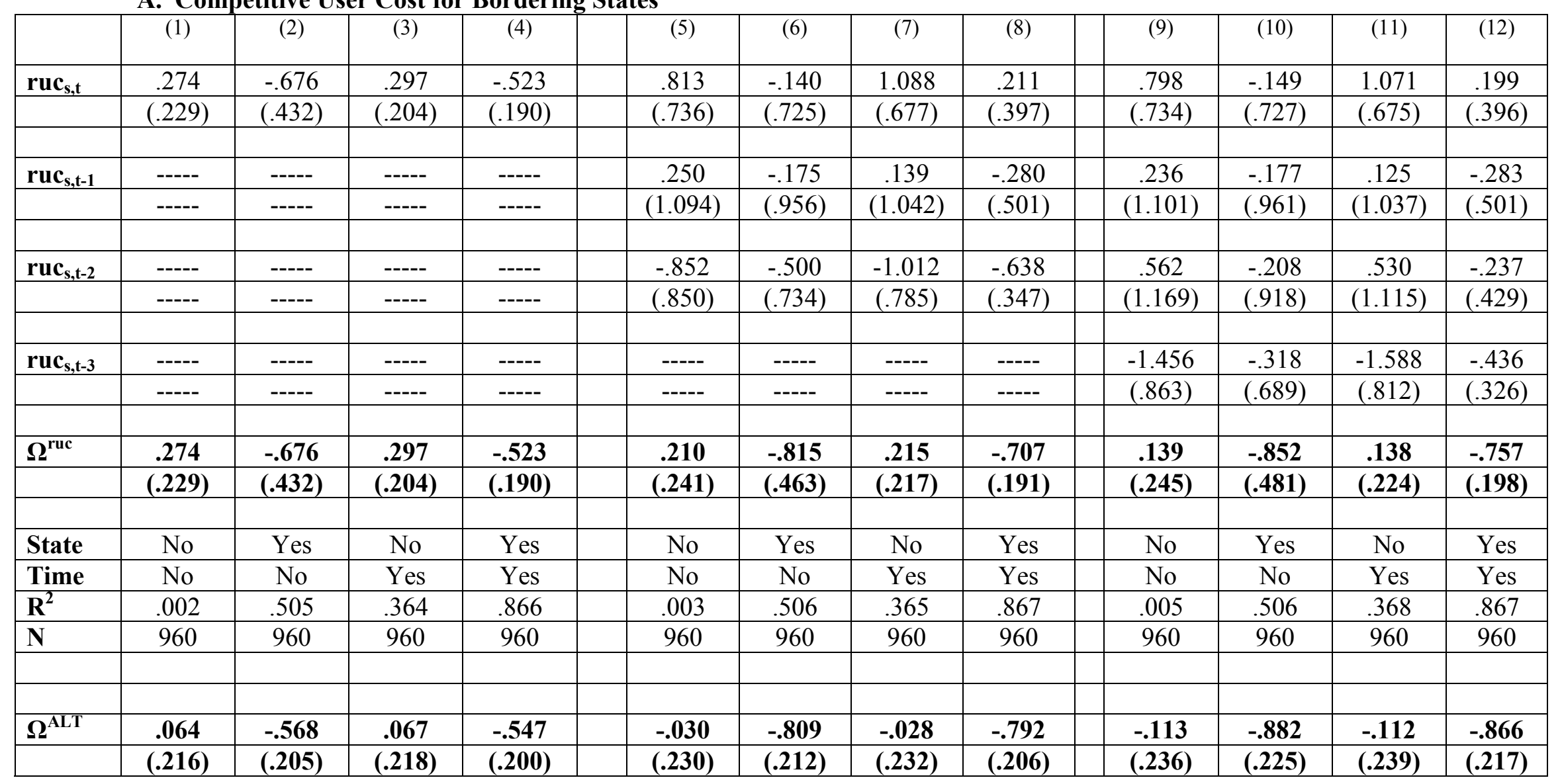


Table 2: Capital Demand Model. Equation (6)

(cont.) Dependent Variable: Logarithm of the Capital/Output Ratio

Various Lags and Fixed Effects

B. Competitive User Cost for the Five Closest States

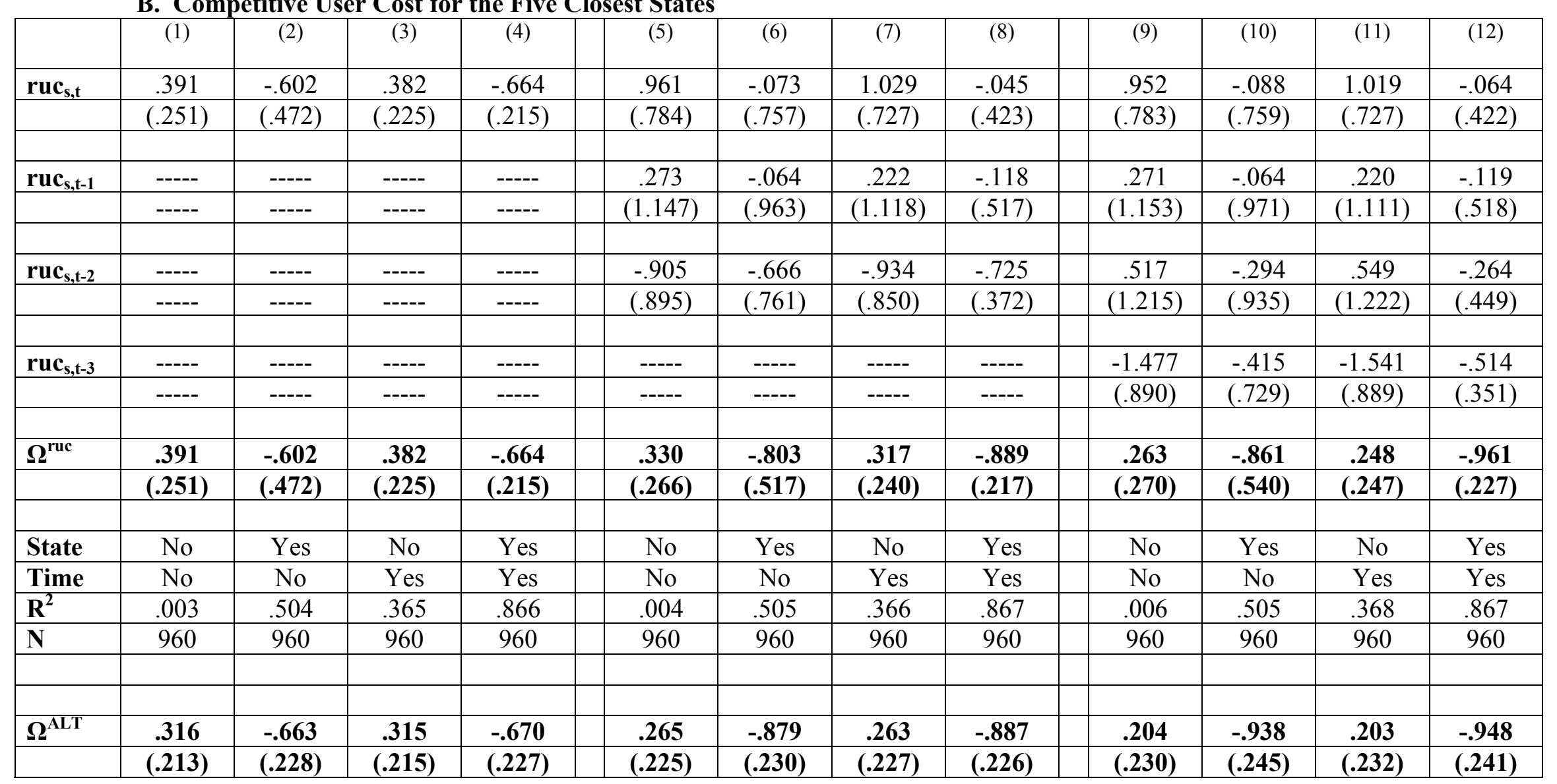


Table 2: Capital Demand Model. Equation (6)

(cont.) Dependent Variable: Logarithm of the Capital/Output Ratio

Various Lags and Fixed Effects

C. Competitive User Cost for All States Weighted by Trade Flows

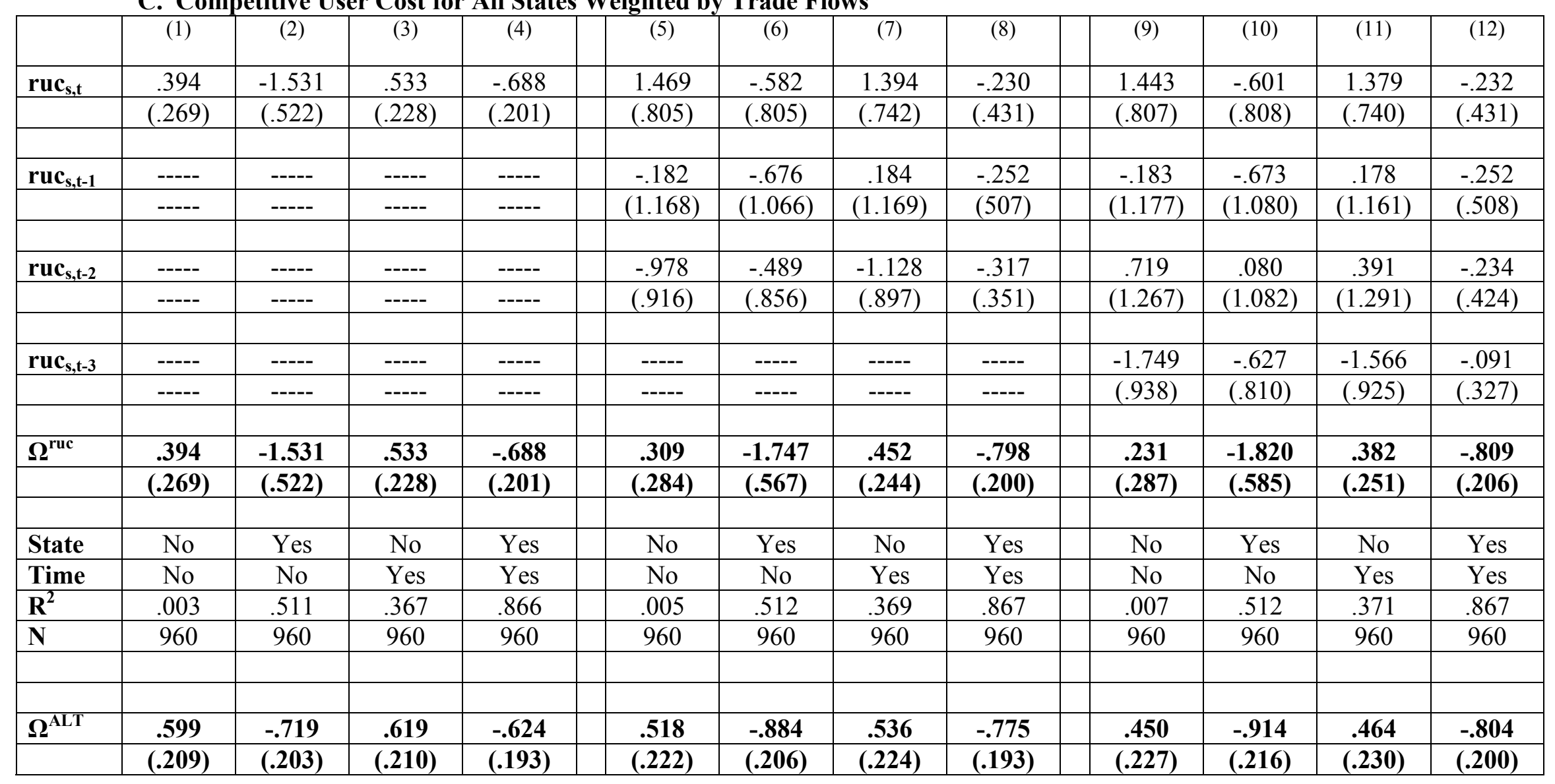




\section{Notes to Table 2:}

OLS estimates are based on equation (6), with the exception of the entry in the last two rows $\left(\Omega^{\mathrm{ALT}}\right.$, discussed below), and on panel data for 48 states for the period 1982 to 2004 . Given the three lags, the effective sample is for the period 1985 to 2004. To enhance comparability across models, the sample is identical for all models appearing in Table 2. The dependent variable is the logarithm of the capital/output ratio for state $\mathrm{s}\left(\mathrm{ky}_{\mathrm{s}, \mathrm{t}}\right)$. The independent variable is the relative user cost for state $\mathrm{s}\left(\mathrm{ruc}_{\mathrm{s}, \mathrm{t}}\right)$ defined as the logarithm of the own-state user cost ( $\mathrm{uc}_{\mathrm{own}} \mathrm{s,t}$ ) less the logarithm of the competitive-states user cost (uc-comp $\mathrm{s}_{\mathrm{s}, \mathrm{t}}$ ). The competitive set of states is defined by the bordering states (Panel A), the five closest states (Panel B), or by all states other than state s (Panel C). The competitive user costs are a weighted-average of the user costs for the states defining the competitive set. For Panels A and $\mathrm{B}$, the weights are the inverse of the distance between the population centroids for state $\mathrm{s}$ and that of a competitive state, normalized to sum to unity; for Panel $\mathrm{C}$, the weights are the trade flows from the remaining 47 states to state s, normalized to sum to unity. See Section 2 and the Data Appendix for further details about data sources and construction. The models in columns (1), (5), and (9) contain no fixed effects (when state fixed effects are absent, a constant term is included); the models in columns (2), (4), (6), (8), (10), and (12) contain state fixed effects; the models in columns (3), (4), (7), (8), (11) and (12) contain time fixed effects. The $\Omega^{\text {ruc }}$ parameter measures the long-run impact of a change in ruc and is defined in equation (6i) as the sum of the immediately preceding coefficients on the ruc $\mathrm{c}_{\mathrm{s}, \mathrm{t}}$ variables. Standard errors are heteroscedastic consistent using the technique of White (1980); the standard error for $\Omega^{\text {ruc }}$ is the sum of the underlying variances and covariances raised to the one-half power. The $\mathrm{R}^{2}$ measures the fraction of total variation measured by the model (including that explained by state and/or year effects, when included). $\mathrm{N}$ is the number of state/year observations. The $\Omega^{\mathrm{ALT}}$ parameter measures the long-run impact of a change in ruc, is based on equation (9) with three additional lags of the independent variable, and is the sum of the coefficients on the four ruc $\mathrm{s}_{\mathrm{s}, \mathrm{t}-\mathrm{n}}$ variables, $\mathrm{n}=0,3$. 
Table 3: Capital Demand Model: Equation (6)

Dependent Variable: Logarithm of the Capital/Output Ratio

Alternative Specifications of the User Cost

Sum of Coefficients on the User Cost Variables ( $\Omega^{\text {ruc }}$ )

\begin{tabular}{|c|c|c|c|}
\hline \multicolumn{4}{|c|}{ A. Omit One or More Tax Components of the User Cost } \\
\hline $\begin{array}{l}\text { Component(s) } \\
\text { Omitted From The } \\
\text { User Cost }\end{array}$ & Bordering States & Five Closest States & $\begin{array}{l}\text { All States Weighted } \\
\text { by Trade Flows }\end{array}$ \\
\hline & (1) & (2) & (3) \\
\hline None & $\begin{array}{l}-.757 \\
(.198)\end{array}$ & $\begin{array}{l}-.961 \\
(.227)\end{array}$ & $\begin{array}{l}-.809 \\
(.206)\end{array}$ \\
\hline $\operatorname{ITC}_{\mathbf{s}, \mathbf{t}}^{\mathrm{L}, \mathrm{S}}$ & $\begin{array}{l}-3.084 \\
(.847) \\
\end{array}$ & $\begin{array}{l}-3.747 \\
(.976)\end{array}$ & $\begin{array}{l}-3.277 \\
(.878) \\
\end{array}$ \\
\hline ITC $_{t}^{\mathrm{L}, \mathrm{F}}$ & $\begin{array}{l}-.861 \\
(.210)\end{array}$ & $\begin{array}{l}-1.108 \\
(.243)\end{array}$ & $\begin{array}{l}-.984 \\
(.217)\end{array}$ \\
\hline $\mathrm{ITC}_{\mathrm{s}, \mathrm{t}}^{\mathrm{L}, \mathrm{S}}$ and $\mathrm{ITC}_{t}^{\mathrm{L}, \mathrm{F}}$ & $\begin{array}{l}-3.352 \\
(.830)\end{array}$ & $\begin{array}{l}-3.786 \\
(.928)\end{array}$ & $\begin{array}{l}-3.616 \\
(.853)\end{array}$ \\
\hline$\tau_{\mathbf{s , t}}^{\mathbf{E}, \mathbf{S}}$ & $\begin{array}{l}-.782 \\
(.215)\end{array}$ & $\begin{array}{l}-1.074 \\
(.251)\end{array}$ & $\begin{array}{l}-.836 \\
(.226)\end{array}$ \\
\hline$\tau_{\mathbf{s}, \mathbf{t}}^{\mathbf{E}, \mathbf{F}}$ & $\begin{array}{r}-1.145 \\
(.274) \\
\end{array}$ & $\begin{array}{l}-1.552 \\
(.322) \\
\end{array}$ & $\begin{array}{l}-1.237 \\
(.272) \\
\end{array}$ \\
\hline$\tau_{\mathbf{s}, \mathbf{t}}^{\mathbf{E}, \mathbf{S}}$ and $\tau_{\mathbf{s , t}}^{\mathbf{E}, \mathbf{F}}$ & $\begin{array}{r}-1.224 \\
(.294)\end{array}$ & $\begin{array}{l}-1.729 \\
(.352)\end{array}$ & $\begin{array}{l}-1.368 \\
(.296)\end{array}$ \\
\hline $\mathbf{P T}_{\mathrm{s}, \mathrm{t}}$ & $\begin{array}{l}-.262 \\
(.165) \\
\end{array}$ & $\begin{array}{l}-.260 \\
(.186)\end{array}$ & $\begin{array}{l}-.292 \\
(.191)\end{array}$ \\
\hline \multicolumn{4}{|c|}{ B. Replace the User Cost with an Average Tax Rate } \\
\hline $\operatorname{ATR}_{\mathrm{s}, \mathrm{t}}^{1}$ & $\begin{array}{c}.014 \\
(.026)\end{array}$ & $\begin{array}{c}.022 \\
(.026)\end{array}$ & $\begin{array}{l}.028 \\
(.030)\end{array}$ \\
\hline $\mathrm{ATR}_{\mathrm{s}, \mathrm{t}}^{2}$ & $\begin{array}{l}.022 \\
(.028)\end{array}$ & $\begin{array}{l}.024 \\
(.027)\end{array}$ & $\begin{array}{l}.049 \\
(.032)\end{array}$ \\
\hline
\end{tabular}




\section{Notes to Table 3:}

OLS estimates are based on equation (6) and on panel data for 48 states. In Panel A, the sample period is 1982 to 2004; given the three lags, the effective sample period is 1985 to 2004. In Panel B, the sample period for $\mathrm{ATR}_{\mathrm{s}, \mathrm{t}}^{1}$ is 1982 to 2004 with missing data for 1998 to 2000; given the three lags and the missing data, the effective sample period is 1985 to 1997 and 2004. Also in Panel B, ATR ${ }_{\mathrm{s}, \mathrm{t}}^{2}$ has the same sample period as $\mathrm{ATR}_{\mathrm{s}, \mathrm{t}}^{1}$ and is missing data for 2001; given the three lags and the missing data, the effective sample period is 1985 to 1997. The dependent variable $\left(\mathrm{ky}_{\mathrm{s}, \mathrm{t}}\right)$ and the independent variable $\left(\mathrm{ruc}_{\mathrm{s}, \mathrm{t}}\right)$ are discussed in the Notes to Table 2. All models contain both state and time fixed effects. The $\Omega^{\text {ruc }}$ parameter measures the long-run impact of a change in ruc and is defined in equation (6i) as the sum of the coefficients on the relative user cost variables. Standard errors are heteroscedastic consistent using the technique of White (1980); the standard error for $\Omega^{\text {ruc }}$ is the sum of the underlying variances and covariances raised to the one-half power. The user cost variables in Panel A are defined according to equations (1) and (2) with one or more of the tax components set to zero (with the exception of the first row). The user cost variables in Panel B are defined as average tax rates; $\mathrm{ATR}_{\mathrm{s}, \mathrm{t}}^{1}$ and $\mathrm{ATR}_{\mathrm{s}, \mathrm{t}}^{2}$ are the alternative average tax rate measures. Each is calculated as state government tax revenues divided by the state private gross operating surplus. $\mathrm{ATR}_{\mathrm{S}, \mathrm{t}}^{1}$ is based on revenues from corporate income taxes, severance taxes, and license fees. ATR2 is based on these revenue sources, as well as state property tax revenues. 
Table 4: Capital Demand Model: Equations (6), (14), (15), and (16) Dependent Variable: Logarithm of the Capital/Output Ratio Various Dynamic Specifications

\begin{tabular}{|c|c|c|c|c|c|c|c|c|c|c|c|c|}
\hline & \multicolumn{4}{|c|}{ Bordering States } & \multicolumn{4}{|c|}{ Five Closest States } & \multicolumn{4}{|c|}{$\begin{array}{c}\text { All States Weighted by } \\
\text { Trade Flows }\end{array}$} \\
\hline & OLS & OLS & NLS & OLS & OLS & OLS & NLS & OLS & OLS & OLS & NLS & OLS \\
\hline & (1) & (2) & (3) & (4) & (5) & (6) & (7) & (8) & (9) & (10) & (11) & (12) \\
\hline ruc $_{\mathrm{s}, \mathrm{t}}$ & .199 & -.192 & - & .257 & -.064 & -.217 & ---- & -.019 & -.232 & -.217 & $\begin{array}{ll}--- \\
\end{array}$ & .004 \\
\hline & $(.396)$ & $(.119)$ & ----- & $(.307)$ & $(.422)$ & $(.127)$ & ---- & $(.331)$ & $(.431)$ & $(.121)$ & ----- & $(.344)$ \\
\hline $\operatorname{ruc}_{\mathrm{s}, \mathrm{t}-1}$ & -.283 & $\begin{array}{ll}--- \\
\end{array}$ & ----- & -.167 & -.119 & ----- & ---- & .026 & -.252 & ----- & ------ & -.270 \\
\hline & $(.501)$ & ----- & ----- & $(.391)$ & $(.518)$ & ----- & ----- & $(.401)$ & $(.508)$ & ----- & ----- & $(.393)$ \\
\hline ruc $_{\mathrm{s}}$ & -.237 & ----- & ----- & -.489 & -.264 & ---- & ----- & -.520 & -.234 & ----- & ----- & -.096 \\
\hline & $(.429)$ & ----- & ----- & $(.286)$ & $(.449)$ & ----- & ------ & $(.305)$ & $(.424)$ & ----- & ----- & $(.281)$ \\
\hline ruc & -436 & ----- & ----- & --o- & -514 & ---- & -.-- & ----- & -091 & ----- & ---- & $\ldots$ \\
\hline Nons, & $(.326)$ & ----- & ---- & ----- & $(.351)$ & ---- & ----- & ---- & $(.327)$ & ---- & ----- & - \\
\hline & & & & & & & & & & & & \\
\hline $\mathbf{k} \mathbf{y}_{\mathrm{s}, \mathrm{t}-3}$ & ----- & |---- & ---- & 457 & ---- & ----- & ----- & 456 & ---- & ----- & ----- & .458 \\
\hline & ----- & ----- & ----- & $(.065)$ & ----- & ----- & ----- & $(.065)$ & ----- & ----- & ----- & $(.065)$ \\
\hline & & & & & & & & & & & & \\
\hline$\lambda$ & ----- & .272 & .229 & ----- & ----- & .272 & .230 & ----- & ----- & .272 & .229 & ----- \\
\hline & ----- & $(.050)$ & $\begin{array}{l}.017) \\
\end{array}$ & ----- & ----- & $(.050)$ & $\begin{array}{l}(.017) \\
\end{array}$ & ----- & ----- & $\begin{array}{l}(.050) \\
\end{array}$ & (.017) & ----- \\
\hline$\Omega^{\text {ruc }}$ & -.757 & -.706 & $\begin{array}{l}-.723 \\
\end{array}$ & -.872 & $\begin{array}{l}.961 \\
\end{array}$ & $\begin{array}{ll}-.798 \\
\end{array}$ & -.905 & -1.129 & -.809 & -.798 & -.681 & -.792 \\
\hline & (.198) & $\begin{array}{l}(.447) \\
\end{array}$ & $\begin{array}{l}(.348) \\
\end{array}$ & $\begin{array}{l}.399) \\
\end{array}$ & $(.227)$ & $(.468)$ & $(.389)$ & $(.478)$ & $(.206)$ & $(.441)$ & $(.383)$ & $(.472)$ \\
\hline & & & & & & & & & & & & \\
\hline State & $\begin{array}{l}\text { Yes } \\
\text { s. }\end{array}$ & Yes & Yes & Yes & Yes & Yes & Yes & Yes & Yes & Yes & Yes & Yes \\
\hline Time & Yes & Yes & Yes & Yes & Yes & Yes & Yes & Yes & Yes & Yes & Yes & Yes \\
\hline $\mathbf{R}^{2}$ & .733 & .872 & .886 & .787 & .733 & .872 & .886 & .787 & .732 & .872 & .886 & .786 \\
\hline $\mathbf{N}$ & 960 & 960 & 960 & 960 & 960 & 960 & 960 & 960 & 960 & 960 & 960 & 960 \\
\hline
\end{tabular}




\section{Notes to Table 4:}

OLS estimates in columns (1), (5), and (9) are based on equation (6) (which is equivalent to equation (13)); OLS estimates in columns (2), (6), and (10) are based on equation (14);

nonlinear least squares (NLS) estimates in columns (3), (7), and (11) are based on equation (15); OLS estimates in columns (4), (8), and (12) are based on equation (16). All estimates are based on panel data for 48 states for the period 1982 to 2004 . Given the three lags, the effective sample is for the period 1985 to 2004 . To enhance comparability across models, the sample is identical for all models appearing in Table 4 . The dependent variable $\left(\mathrm{ky}_{\mathrm{s}, \mathrm{t}}\right)$ and the independent variable $\left(\mathrm{ruc}_{\mathrm{s}, \mathrm{t}}\right)$ are discussed in the Notes to Table 2. All models contain both state and time fixed effects. Standard errors are heteroscedastic consistent using the technique of White (1980). The $\Omega^{\text {ruc }}$ parameter measures the long-run impact of a change in ruc and is computed three different ways. In columns (1), (5), and (9), $\Omega^{\text {ruc }}$ is the sum of the immediately preceding four coefficients on the ruc $\mathrm{s}_{\mathrm{s}, \mathrm{t}}$ variables (as defined in equation (6i)); the standard error for $\Omega^{\text {ruc }}$ is the sum of the underlying variances and covariances raised to the one-half power. In columns (2), (6), and (10), $\Omega^{\text {ruc }}$ is estimated as a transformation of the OLS coefficients (see equation (14c)); the standard error for $\Omega^{\text {ruc }}$ is computed by the delta method. In columns (3), (7), and (11), $\Omega^{\text {ruc }}$ is estimated directly by NLS.; the standard error for $\Omega^{\text {ruc }}$ is computed by NLS. In columns (4), (8), and (12), $\Omega^{\text {ruc }}$ is the sum of the immediately preceding three coefficients on the ruc $_{\mathrm{s}, \mathrm{t}}$ variables divided by one minus the coefficient on $\mathrm{ky}_{\mathrm{t}-3}$ (see equation (16b)); the standard error for $\Omega^{\text {ruc }}$ is computed by the delta method. The $\mathrm{R}^{2}$ measures the fraction of total variation measured by the model (including that explained by state and/or year effects). $\mathrm{N}$ is the number of state/year observations. 
Table 5: Capital Demand Model: Equations (6) and (17) Dependent Variable: Logarithm of the Capital/Output Ratio Relative and Separate User Cost Specifications

\begin{tabular}{|c|c|c|c|c|c|c|c|}
\hline & \multirow{2}{*}{$\begin{array}{c}\text { Own- } \\
\text { State } \\
(1)\end{array}$} & \multicolumn{2}{|c|}{ Bordering States } & \multicolumn{2}{|c|}{$\begin{array}{c}\text { Five Closest } \\
\text { States }\end{array}$} & \multicolumn{2}{|c|}{$\begin{array}{c}\text { All States } \\
\text { Weighted by } \\
\text { Trade Flows }\end{array}$} \\
\hline & & (2) & (3) & (4) & (5) & (6) & (7) \\
\hline$\Omega^{\mathrm{ruc}}$ & ---- & -.757 & ---- & -.961 & ---- & -.808 & ---- \\
\hline & $\begin{array}{ll}----- \\
\end{array}$ & $(.198)$ & $\begin{array}{ll}---- \\
\end{array}$ & $(.227)$ & ----- & $(.206)$ & $\begin{array}{ll}---- \\
\end{array}$ \\
\hline$\Omega^{\mathrm{uc-own}}$ & -.713 & $\begin{array}{ll}---- \\
\end{array}$ & -.743 & ----- & -.893 & ----- & -.709 \\
\hline & $(.224)$ & ----- & $(.221)$ & ----- & $(.229)$ & ----- & $(.226)$ \\
\hline$\Omega^{\text {uc-comp }}$ & ----- & $\begin{array}{ll}----- \\
\end{array}$ & .837 & ----- & 1.499 & ----- & 1.819 \\
\hline & $\begin{array}{ll}---- \\
\end{array}$ & $\begin{array}{ll}---- \\
\end{array}$ & $(.338)$ & $\begin{array}{ll}---- \\
---\end{array}$ & $(.533)$ & $\begin{array}{ll}---- \\
---\end{array}$ & $(.677)$ \\
\hline $\mathbf{\Omega}^{\mathrm{SUM}}$ & ----- & ----- & .094 & ----- & .605 & ----- & 1.110 \\
\hline & ----- & ----- & $(.376)$ & ----- & $(.534)$ & ----- & $(.749)$ \\
\hline State & Yes & Yes & Yes & Yes & Yes & Yes & Yes \\
\hline Time & Yes & Yes & Yes & Yes & Yes & Yes & Yes \\
\hline $\mathbf{R}^{2}$ & .866 & .867 & .868 & .867 & .869 & .867 & .867 \\
\hline $\mathbf{N}$ & 960 & 960 & 960 & 960 & 960 & 960 & 960 \\
\hline
\end{tabular}

\section{Notes to Table 5:}

OLS estimates in columns (1), (3), (5), and (7) are based on equation (17); OLS estimates in columns (2), (4), and (6) are based on equation (6). All estimates are based on panel data for 48 states for the period 1982 to 2004. Given the three lags, the effective sample is for the period 1985 to 2004. To enhance comparability across models, the sample is identical for all models appearing in Table 5. The dependent variable $\left(\mathrm{ky}_{\mathrm{s}, \mathrm{t}}\right)$ and the independent variables $\left(\right.$ ruc $_{\mathrm{s}, \mathrm{t}}, \mathrm{uc}-\mathrm{own}_{\mathrm{s}, \mathrm{t}}$, and uc-comp $\left.\mathrm{s,t}\right)$ are discussed in the Notes to Table 2. All models contain both state and time fixed effects. The $\Omega^{\text {ruc }}, \Omega^{\text {uc-own }}$, and $\Omega^{\text {uc-comp }}$ parameters measure the longrun impact of a change in ruc, uc-own, and uc-comp, respectively, and are the sum of the four coefficients on their user cost variables (the individual coefficients are not reported owing to space constraints). The $\Omega^{\mathrm{SUM}}$ statistic evaluates the net impact of equal changes in own-state and competitive-states user costs and equals the sum of $\Omega^{\text {uc-own }}$ and $\Omega^{\text {uc-comp }}$. Standard errors are heteroscedastic consistent using the technique of White (1980); the standard errors for the $\Omega$ 's are the sum of the underlying variances and covariances associated with a given $\Omega$ raised to the one-half power. The $\mathrm{R}^{2}$ measures the fraction of total variation measured by the model (including that explained by state and/or year effects). $\mathrm{N}$ is the number of state/year observations. 
Table 6: Establishment Count Model: Equation (20)

Dependent Variable: Logarithmic Difference of Establishment Counts in Twin-Counties

\begin{tabular}{|l|c|}
\hline & Twin-Counties \\
\hline ruc $_{\mathrm{p}, \mathrm{t}}$ & -.052 \\
\hline & $(.044)$ \\
\hline ruc $_{\mathrm{p}, \mathrm{t}-\mathrm{1}}$ & .008 \\
\hline & $(.065)$ \\
\hline ruc $_{\mathrm{p}, \mathrm{t}-2}$ & .058 \\
\hline & $(.067)$ \\
\hline & \\
\hline ruc $_{\mathrm{p}, \mathrm{t}-3}$ & -.092 \\
\hline & $(.052)$ \\
\hline & \\
\hline$\Omega^{\text {ruc }}$ & -.078 \\
\hline & $(.031)$ \\
\hline & \\
\hline $\mathrm{R}^{2}$ & .958 \\
\hline $\mathrm{N}$ & 38,765 \\
\hline $\mathrm{N}-$ Twins & 1,877 \\
\hline
\end{tabular}

Notes to Table 6:

OLS estimates are based on equation (20) and on panel data for all counties in the 48 states for the period 1977 to 2004 . Given the three lags, the effective sample is for the period 1980 to 2004. The dependent variable is the difference in the logarithm of the establishment counts for a pair (p) of twin-counties. The independent variable is the relative user cost for a pair of twin-counties, defined as the logarithm of the user cost for the state in which county c' is located less the logarithm of the user cost for the state in which the twin-county, c", is located. Twin-counties are defined in a four step procedure described in Section 4.1. See Section 2 and the Data Appendix for further details about data sources and construction. The model contains fixed effects for each pair of counties. The $\Omega^{\text {ruc }}$ parameter measures the longrun impact of a change in ruc and is the sum of the immediately preceding coefficients on the ruc $_{\mathrm{p}, \mathrm{t}}$ variables. Standard errors are heteroscedastic consistent and robust to clustering using using the technique of Rogers (1993), which is an extension of White (1980); the standard error for $\Omega^{\text {ruc }}$ is the sum of the underlying variances and covariances raised to the one-half power. The $\mathrm{R}^{2}$ measures the fraction of total variation measured by the model (including that explained by paired-county fixed effects). $\mathrm{N}$ is the number of state/year observations. $\mathrm{N}$ Twins is the number of twin-counties given the selection procedure described in Section 4.2. 